\title{
Untangling competition between epitaxial strain and growth stress through examination of variations in local oxidation
}

\section{Maria Yankova}

University of Manchester https://orcid.org/0000-0002-0972-6700

\section{Alistair Garner}

University of Manchester

Felicity Baxter

University of Manchester

\section{Samual Armson}

University of Manchester

\section{Christopher Race}

University of Manchester

Michael Preuss ( $\nabla$ michael.preuss@monash.edu )

University of Manchester

\section{Philipp Frankel}

University of Manchester

\section{Article}

Keywords: oxide formation, corrosion, high-performance alloys

Posted Date: October 6th, 2021

DOl: https://doi.org/10.21203/rs.3.rs-926825/v1

License: (c) (i) This work is licensed under a Creative Commons Attribution 4.0 International License. Read Full License 
3

4

5

6

\author{
Authors \\ Maria S. Yankova ${ }^{1 *}$, Alistair Garner ${ }^{1}$, Felicity Baxter ${ }^{1}$, Samuel Armson ${ }^{1}$, Christopher P. \\ Race $^{1}$, Michael Preuss ${ }^{1,2} \uparrow$, Philipp Frankel ${ }^{1}$ \\ Affiliations \\ ${ }^{1}$ Materials Performance Centre, Department of Materials, the University of Manchester, \\ Manchester M13 9PL, UK \\ ${ }^{2}$ Department of Materials Science \& Engineering, Monash University, Clayton, 3800, \\ Victoria, Australia \\ *maria.yankova@manchester.ac.uk \\ †michael.preuss@manchester.ac.uk
}

\begin{abstract}
Understanding oxide formation during corrosion of high-performance alloys in harsh environments is of great fundamental and industrial interest and provides a potential route for reducing the significant annual cost of corrosion globally. However, corrosion mechanisms involve multiple length scales, requiring a multitude of advanced experimental procedures. Here, we use correlated high resolution electron microscopy techniques over a range of length scales, combined with crystallographic modelling to show that there is a clear competition between epitaxial strain and growth stress during oxidation. The degree to which these competing mechanisms operate is shown to depend on the orientation of the substrate grains leading to significant local variations in oxide microstructure and thus protectiveness, even across a single sample. This leads to the possibility of tailoring substrate crystallographic textures in order to promote gradual phase transformation and the development of stress driven, well-oriented protective oxides, and so to improving overall corrosion performance.
\end{abstract}

\title{
Main text
}

As a result of a spontaneous electrochemical reaction with the environment, most metals corrode by forming a metal oxide film. This oxide film may protect the metal substrate against further oxidation depending on a combination of numerous competing mechanisms that operate at a range of length scales. Corrosion costs have been estimated to be around 3\% $-4 \%$ of each nation's gross domestic product (GDP) or the equivalent of US\$ 2.5 trillion globally in $2013^{1}$. Hence, there is a great financial incentive to reduce corrosion through better understanding of corrosion mechanisms.

The crystallographic orientation of the metal grains is an important factor that affects the corrosion rate in many metals and alloys. Studies of both polycrystalline materials ${ }^{2-4}$ and single crystals ${ }^{5-7}$ have shown that corrosion properties can vary significantly over a few degrees difference in crystallographic orientation. The main effect has been attributed to the metallic dissolution rates, expected to scale directly with the surface energy of the crystallographic planes - close-packed planes have a higher atomic density and binding energy, and thus show superior corrosion resistance. This trend was confirmed in experimental studies in a wide range of metals - body-centred-cubic materials, such as $\mathrm{Fe}^{2}$ 
and $\mathrm{Cr}^{8}$; face-centred-cubic materials, such as $\mathrm{Ni}^{9-11}$, Ni-based alloy $22^{12}, \mathrm{Cu}^{13}$ and Inconel $600^{14}$; and hexagonal-close-packed materials, such as $\mathrm{Mg}^{4,15}, \mathrm{Zn}^{16}, \mathrm{Ti}^{17}$ and $\mathrm{Zr}^{7,18-20}$. In parallel, theoretical calculations using first-principles ${ }^{21-23}$ and empirical-potential ${ }^{24-26}$ methods confirmed the above hypothesis by calculating the surface energies and energy barriers for diffusion along the different crystal directions.

The orientation of the metal grain may also directly affect various aspects of the oxide microstructure - such as crystallographic orientation, oxide phases, grain size and shape. The first is a result of lattice matching between the metal substrate and the growing oxide that is a preferential adoption of an orientation relationship, or epitaxial relationship, between two lattices, where interfacial planes share similar atomic spacing ${ }^{27}$. Epitaxial strains develop, which drive the growth of specific crystallographic texture components in the oxide, thus affecting the lattice and grain boundary resistance to diffusion of corroding species. Cathcart et al. ${ }^{9}$ used X-ray diffraction (XRD) to measure the epitaxial orientation relationships in the $\mathrm{Ni}-\mathrm{NiO}$ system for various faces of single Ni grains. They found a correlation between the fraction of high-angle grain boundaries in $\mathrm{NiO}$ and the protectiveness of the oxide layer, later confirmed by other studies ${ }^{10,11,28}$. In the dual-phase $\mathrm{Zr}-2.5 \% \mathrm{Nb}$ alloys with a well-defined substrate texture, bulk XRD oxide texture measurements established lattice matching between different metal faces and the $\mathrm{ZrO}_{2}$ film during oxide nucleation, followed by a preferential growth of specific oxide orientations ${ }^{29}$. In contrast, single-phase $\mathrm{Zr}$ alloys with typical 'split-basal' texture ${ }^{30}$ (characterised by a $20^{\circ}$ to $40^{\circ}$ incline of the c-axis of the hcp- $\mathrm{Zr}$ lattice with respect to the surface) did not show strong oxide texture or effects on corrosion kinetics ${ }^{31}$. This lack of effect is an artefact of measuring the macrotexture of the material and, as we will show later, metal-oxide orientation relationships do in fact form in single-phase $\mathrm{Zr}$ alloys.

Another important factor is the volume change associated with the metal-to-oxide transformation, also referred to as the Pilling-Bedworth ratio ${ }^{32}$. Protective oxides require a ratio larger than one, i.e. the volume of the elementary cell of a metal oxide is larger than that of the corresponding metal, although Pilling-Bedworth ratios larger than two can also be less protective due to oxide buckling ${ }^{32,33}$. Example of ratios between 1 and 2 are $\mathrm{Cu}, \mathrm{Ni}, \mathrm{Zn}, \mathrm{Ti}$ and Zr. Notably, the Pilling-Bedworth-ratio 'rule' only applies to those metal-oxide systems in which the oxygen ion diffuses faster through the oxide than the metal ion, resulting in inwards oxide formation. The $\mathrm{Zr}-\mathrm{ZrO}_{2}$ system is a typical example with a Pilling-Bedworth ratio of 1.56 and inwards corrosion — the metal grows a semi-passivating oxide layer under high planar compressive stress ${ }^{34}$.

Associated with the volume expansion of a protective oxide is the build-up of compressive stresses, which can be in the range of several GPa ${ }^{35,36}$. These large compressive stresses impact oxide grain growth, and thereby grain nucleation, as the oxide will grow so as to minimise its biaxial or triaxial stress state ${ }^{37-39}$. When we consider the influence of the volume change together with the orientation and the elastic anisotropy of the metal crystal, it is possible for particular oxide orientations, which maximise the accommodation of volume changes normal to the interface, to grow preferentially. Gray et al. ${ }^{12}$ found that, under certain environmental conditions, the preferential corrosion order of $\mathrm{Ni}$ orientations does not follow the surface energy trend. Instead, faces that are more susceptible to corrosion also formed more protective oxide films. Thus, a competition between the epitaxial strain and the growth stress was identified. Moreover, the growth stresses may stabilise otherwise metastable phases of the oxide, in addition to other stabilising factors such as small grain size and chemical dopants ${ }^{34,40}$. During the oxidation of zirconium alloys in typical light-water nuclear reactor operating conditions, the metastable hexagonal sub-oxide $\mathrm{ZrO}^{41}$ as well as metastable tetragonal $\mathrm{ZrO}_{2}$ along with the stable monoclinic $\mathrm{ZrO}_{2}$ are often observed ${ }^{34,42,43}$. The role of 
these metastable phases in the corrosion process is still unclear - phase transformations have been suggested to cause cracking of the oxide film ${ }^{36}$.

Finding strategies for improved corrosion and oxidation control of engineering alloys exposed to harsh environments is key to improving the lifetime of components and even incremental improvements can have substantial consequences: for example, slight improvements in the corrosion performance of zirconium alloys, used to encapsulate nuclear fuel, can dramatically improve efficiencies of nuclear power generation ${ }^{44}$. To date, our understanding of the interplay between metal-oxide crystallographic orientation relationships and oxide growth stresses (and the effect of this interplay on the protectiveness of the oxide) is very limited due to experimental challenges when analysing highly stressed, nanocrystalline oxides over a sufficiently large area or volume. Although bulk techniques such as XRD provide good statistics, they commonly lack the required resolution to directly relate oxide texture to specific metal grain orientations or can only be used in single crystal examinations ${ }^{7,9,11,28,45}$. Alternatively, transmission electron microscopy (TEM) investigations ${ }^{19,28,46,47}$ only focus on a few oxide grains formed on a single randomly selected substrate grain, making a statistical analysis of possible orientation relationships very difficult. By definition, these techniques also require the production of electron transparent samples, which is known to alter the microstructure of such stress-stabilised oxide films ${ }^{48,49}$.

In the present study, we exploit recent technological advances in electron microscopy combined with modelling of idealised crystallographic orientation relationships to directly relate the orientation of a large number of oxide grains to that of the underlying metal grains on a bulk sample, thereby maintaining the constraint in the oxide. To achieve this, we used electron backscatter diffraction (EBSD) at low accelerating voltage to reliably analyse the phase and orientation of a region containing approximately half a million $\mathrm{ZrO}_{2}$ nanograins, followed by analysis of the underlying metal microstructure. We then used scanning precession electron diffraction (SPED) in the TEM to relate the observations to the grain morphology and microtexture of the oxide. In addition, we developed an algorithm to identify an epitaxial orientation relationship between any two crystals, which takes as an input EBSD or SPED orientation data. Through modelling of the possible ideal crystallographic orientation relationships, we have identified new zirconium metal-oxide orientation relationships and the competition between the transformation stress and the epitaxial lattice matching mechanisms during oxide growth affecting both the oxide texture development and oxide phase stabilisation. Our multi-scale analysis approach combined with modelling provides new understanding of the main driving forces for oxide texture and microstructure evolution during aqueous corrosion that is applicable to engineering alloys that display inwards corrosion and have a Pilling-Bedworth ratio between 1 and 2 .

\section{Results}

\section{Electron backscatter diffraction}

After mechanical removal of the rough outer oxide (removing about $400 \mathrm{~nm}$ from an average initial thickness of $\sim 1.2 \mu \mathrm{m}$ ) formed during aqueous corrosion of a commercial single-phase $\mathrm{Zr}$ alloy (Zircaloy-2) in a simulated pressurised water reactor (PWR) environment, an EBSD orientation map was acquired from the polished oxide surface, as seen in Error! Reference source not found.a. The map was obtained using a low accelerating voltage in order to minimise the electron interaction volume and clearly shows that the nanosized oxide grains are grouped into regions with similar crystallographic texture, as outlined and numbered in the figure. Due to the 100-nm step size relative to the average oxide grain diameter of 40-60 $\mathrm{nm}$ when viewed in this orientation ${ }^{39,47}$, each data point most likely corresponds to a unique oxide grain. As a result, we obtained a map containing approximately 560,000 oxide grains 
with $95 \%$ of indexed points being stable monoclinic $\mathrm{ZrO}_{2}\left(\mathrm{~m}-\mathrm{ZrO}_{2}\right)$ and $5 \%$ being metastable tetragonal $\mathrm{ZrO}_{2}\left(\mathrm{t}-\mathrm{ZrO}_{2}\right)$ (stabilised by a combination of small grain size ${ }^{40}$, stress ${ }^{50}$ and oxygen vacancies ${ }^{51}$ ). Monoclinic $\mathrm{ZrO}_{2}$ is the stable phase of zirconia at temperatures up to $1170^{\circ} \mathrm{C}$ with four $\mathrm{ZrO}_{2}$ units per unit cell ${ }^{52}$, whereas between $1170^{\circ} \mathrm{C}$ and $2370^{\circ} \mathrm{C}$ the bodycentred tetragonal (bct) $\mathrm{ZrO}_{2}$ phase with two $\mathrm{ZrO}_{2}$ units per unit cell is stabilised. This crystal structure can also be described by a non-primitive face-centred tetragonal (fct) unit cell containing four $\mathrm{ZrO}_{2}$ units, and so comparison between orientations is based on bet Miller indices of the tetragonal cell and equivalent fct indices of the monoclinic cell.

A grain orientation map acquired from the $\mathrm{Zr}$ substrate after mechanical removal of the oxide is shown in Error! Reference source not found.b. The stable phase $\alpha$-Zr has a hexagonal close-packed crystal structure and hereinafter we refer to that phase as simply $\mathrm{Zr}$. Upon comparison with Error! Reference source not found.a, there is a strong suggestion that the borders of the microtextured oxide areas are related to the orientation of the underlying metal grains. The regions/grains are highlighted accordingly in Error! Reference source not found. $a$ and $b$. The lack of a perfect match can be explained by the difficulty in identifying the exact point at which the metal-oxide interface is reached during removal of the oxide film. In Error! Reference source not found.c cross-sectional SEM images acquired from FIB trenches from each oxide region show the oxide in regions 2 and 2' to be twice as thick as that in regions 1 and 1 '. Further analysis comparing oxide microstructure and crystallographic texture was performed on oxide regions 1 and 2, and the corresponding metal grains. Data from oxide regions 1' and 2' were found to agree with those from regions 1 and 2 , respectively, and results are included as supplementary material.

Firstly, we consider the overall crystallographic texture of the metal grains and oxide regions as measured using EBSD in the contour pole figures in Fig. 2. As seen in Error! Reference source not found.a, the $\mathrm{Zr}$ hcp crystal of grain 1 is positioned so that the basal pole $<0002>_{\mathrm{Zr}}$ is inclined at about $46^{\circ}$ to the normal direction (ND). This inclination is just outside the peak range of $20^{\circ}$ to $40^{\circ}$ corresponding to the typical crystallographic texture in single-phase $\mathrm{Zr}$ alloys used in the nuclear industry ${ }^{30,53}$. This texture is called 'split-basal' due to a symmetrical 'split' of the hcp basal pole with respect to ND ${ }^{30}$. In oxide region 1, we measured 49,938 monoclinic grains and 1,847 tetragonal grains, or a tetragonal phase fraction of $3.6 \%$. We observe that the $<001>$ poles of both the monoclinic and the few indexed tetragonal grains in this region are oriented strongly in the oxide growth direction. The tetragonal $<001>$ also shows four other peaks positioned at $90^{\circ}$ with respect to ND. Error! Reference source not found. $2 \mathrm{~b}$ shows that the $\langle 0002\rangle$ pole of the hep Zr crystal in substrate grain 2 is close to parallel to the normal direction, oriented at $12^{\circ}$. In oxide region 2 , the $<001>$ tetragonal $\mathrm{ZrO}_{2}$ pole figure is formed from 531 tetragonal grains, which, although a limited number, shows a very close to random crystallographic texture. On the other hand, the $<001>$ pole figures, formed from 20,544 measured monoclinic oxide grains, exhibit a six-fold symmetry with stronger preference for two of the texture variants. There is a lower tetragonal phase fraction of $2.5 \%$ compared with region 1 . 

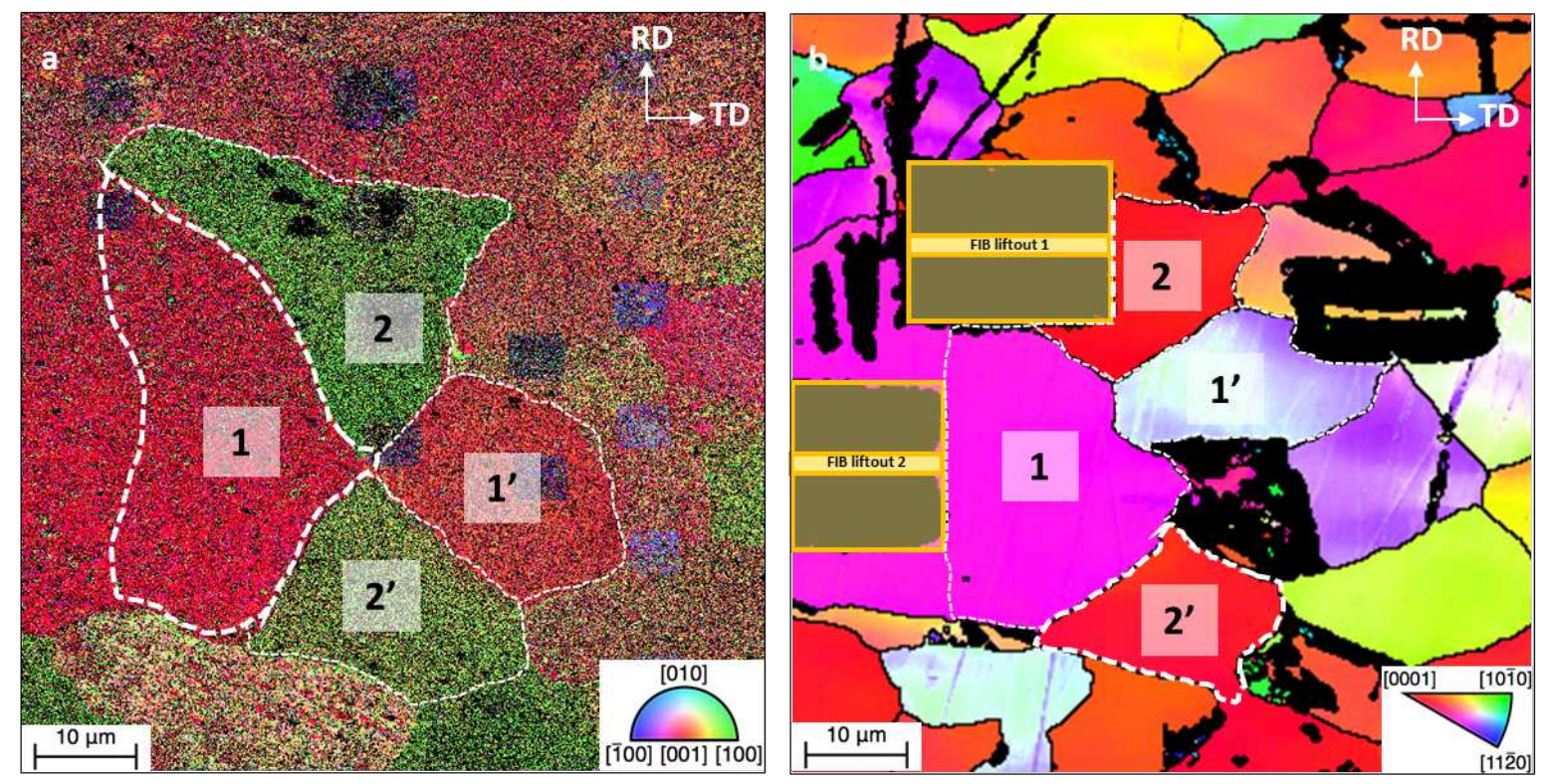

c
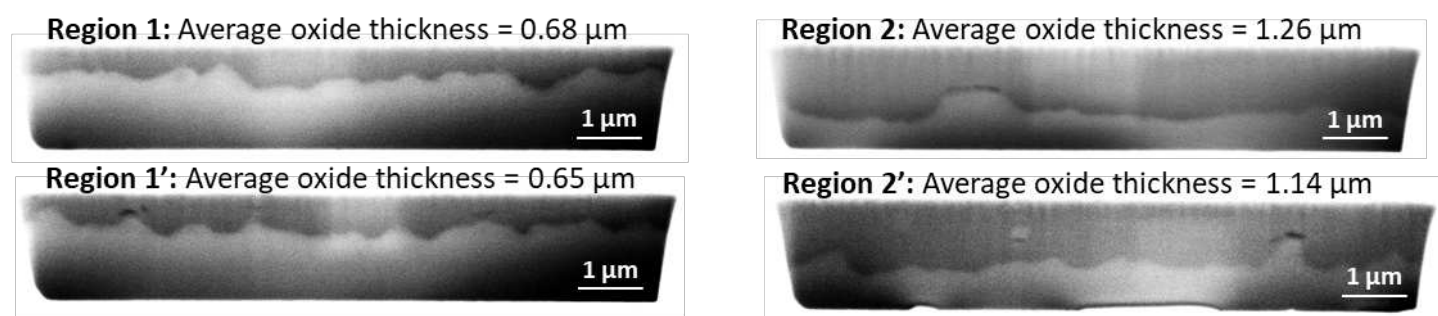

Fig. 1 Electron backscatter diffraction orientation maps. EBSD orientation maps in inverse pole figure colouring relative to ND for $\mathbf{a}$ monoclinic $\mathrm{ZrO}_{2}$ and $\mathbf{b}$ corresponding metal grains after mechanical removal of oxide. Regions for subsequent orientation analysis are labelled. Original rolling (RD) and transverse (TD) directions are marked on the figures. SEM images acquired from FIB trenches from each oxide region are shown in c. Square regions $(\sim 5 \mu \mathrm{m})$ visible in the oxide orientation map are regions of intentional focused-ionbeam (FIB) damage that formed part of another study ${ }^{49}$ and are excluded from this analysis.

Plotting the raw pole figures from the EBSD map for the tetragonal and the monoclinic $\mathrm{ZrO}_{2}$ phases in region 1, Fig. 3a and c, suggests the presence of lattice matching between the metal substrate phase and the tetragonal and/or the monoclinic oxides. We performed further analysis by calculating possible theoretical orientation relationships, which revealed two scenarios. In the first one, denoted by pink discs in Fig. 3c, hcp Zr transforms to tetragonal $\mathrm{ZrO}_{2}$, and then the tetragonal grains transform to monoclinic $\mathrm{ZrO}_{2}$ based on the relationships: $\{111\}<10 \overline{1}>_{\mathrm{m}-\mathrm{ZrO}_{2}}\left\|\{101\}<11 \overline{2}>_{\mathrm{t}-\mathrm{ZrO}_{2}}\right\|\{0002\}<11 \overline{2} 0>_{\mathrm{Zr}}$. In the second one, denoted by blue crosses in Fig. 3c, hcp $\mathrm{Zr}$ can still transform to tetragonal $\mathrm{ZrO}_{2}$ according to $\{101\}<11 \overline{2}>_{\mathrm{t}-\mathrm{ZrO}_{2}} \|\{0002\}<11 \overline{2} 0>_{\mathrm{Zr}}$, and it can also transform directly to monoclinic $\mathrm{ZrO}_{2}$ according to $\{111\}<10 \overline{1}>_{\mathrm{m}-\mathrm{ZrO}_{2}} \|\{0002\}<11 \overline{2} 0>_{\mathrm{Zr}}$. We observe almost equal proportion of the four experimentally measured texture components in the $\{001\}_{\mathrm{m}-\mathrm{ZrO}_{2}}$ and $\{10 \overline{1}\}_{\mathrm{m}-\mathrm{ZrO}_{2}}$ pole figures, which are matched by the theoretical orientations of the first scenario. Therefore, we conclude that the majority of the oxide has formed as a tetragonal phase first, and then transformed to monoclinic. That resolves a longstanding issue of which $\mathrm{ZrO}_{2}$ phase forms first and has important implications for the corrosion process of $\mathrm{Zr}$ alloys to be discussed later. It should also be pointed out that during a 
hexagonal-close-packed to tetragonal phase transformation, 24 possible symmetrically equivalent variants exist. However, the hcp crystal is only 3 -fold rotationally symmetric, and so 12 of the symmetry variants might grow on an exposed A layer of the hcp stacking and another 12 might grow on an exposed B layer. We only observed one of these 12-variant sets in the measured tetragonal phase, which we attribute to a random process due to the transformation of a single $\mathrm{Zr}$ grain. In the next phase transformation, from tetragonal to monoclinic $\mathrm{ZrO}_{2}$, we note that 4 of the 12 variants have grown preferentially, as seen in Fig.

$2142(\mathrm{C})$, to form a strong epitaxial texture with the $\{10 \overline{6}\}_{\mathrm{m}-\mathrm{ZrO}_{2}}$ parallel to the metal-oxide interface. Raw pole figure data plotted from the EBSD maps of the tetragonal and the

216 monoclinic $\mathrm{ZrO}_{2}$ in region 2 are shown in Error! Reference source not found. $3 \mathrm{~b}$ and d.

217 Here, the tetragonal grains do not exhibit a preferential texture. On the other hand, the $\{001\}_{\mathrm{m}-\mathrm{ZrO}_{2}}$ pole figure in d clearly shows two distinct texture components. We looked at different possible oxide orientations that could arise from lattice matching between the hcp $\mathrm{Zr}$ lattice and the monoclinic $\mathrm{ZrO}_{2}$ lattice, and in order to reproduce the experimental results the inclusion of two new epitaxial relationships between the monoclinic oxide and the metal substrate was required. We have identified both of these components to have the $<111>$ monoclinic oxide directions parallel to the $<1 \overline{1} 00>\mathrm{Zr}$ directions but with either the $\{11 \overline{2}\}$ or the $\{31 \overline{2}\}$ oxide planes parallel to the $\{0002\}$ metal plane. The theoretical orientations based on these two epitaxial relationships, i.e. $\{112\}<111>_{\mathrm{m}-\mathrm{ZrO}_{2}} \|\{0002\}<1 \overline{1} 00>_{\mathrm{Zr}}$ and $\{31 \overline{2}\}<111>_{\mathrm{m}-\mathrm{ZrO}_{2}} \|\{0002\}<1 \overline{100}>_{\mathrm{Zr}}$, and the assumption of the metal $<0002>_{\mathrm{Zr}}$ being normal to the metal-oxide interface, are overlaid as orange disks and red crosses, respectively. We see an excellent match between the model and the experimental textures. The fraction of the major texture component was found to be approximately 2.4 times that of the minor component and both components have a spread of $16^{\circ}$ from the ideal orientation 

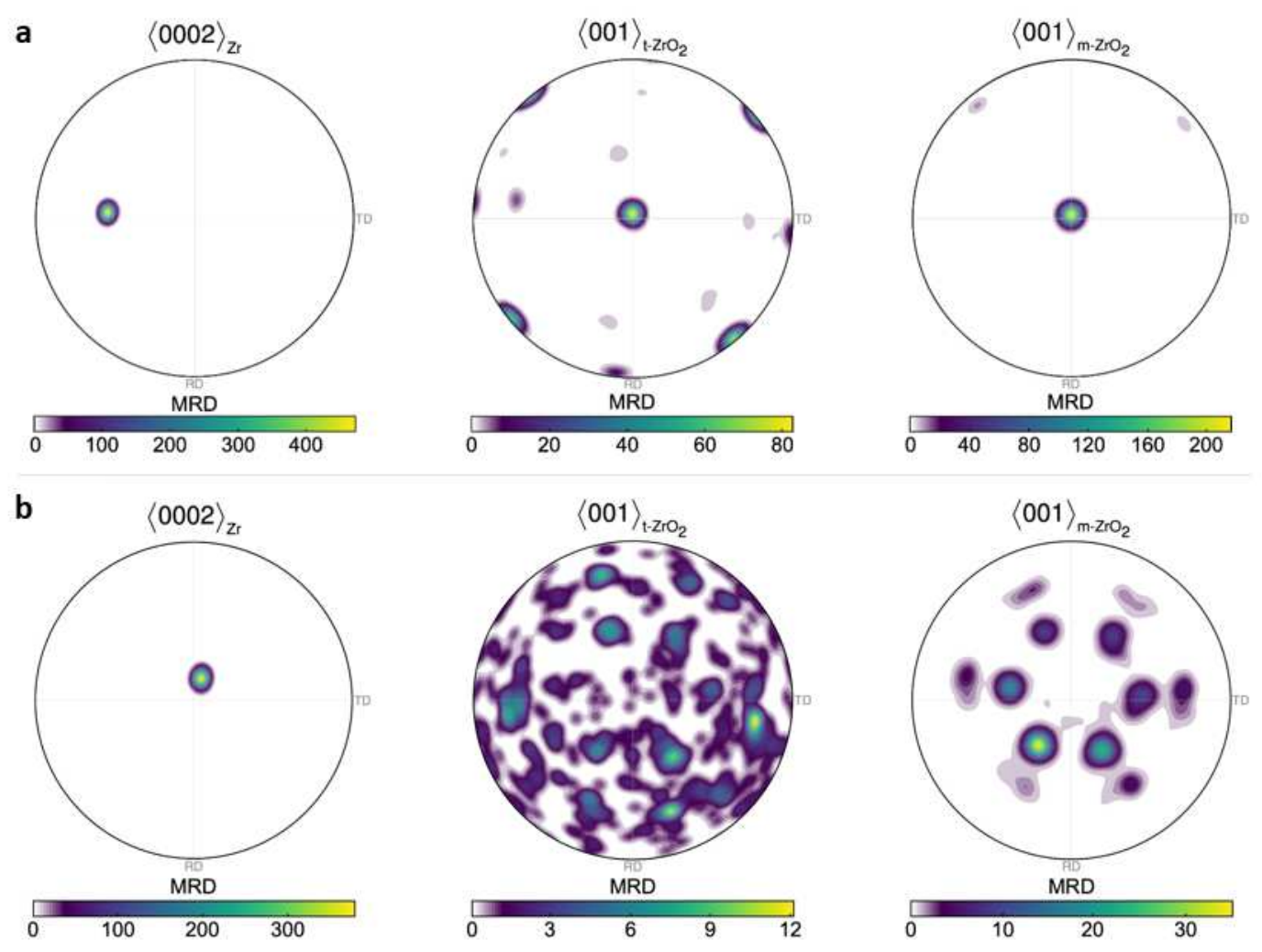

Fig. 2 Electron backscatter diffraction contour pole figures. Contoured pole figures for the $<0002>$ pole in hexagonal $\mathrm{Zr}$, and the $<001>$ poles in tetragonal and monoclinic $\mathrm{ZrO}_{2}$ in metal grain 1 and oxide region 1 (a); metal grain 2 and oxide region 2 (b). All contoured pole figures are normalised to multiples of a random distribution (MRD) and oriented to be consistent with EBSD map in Fig. 1 with TD $\| x$ axis, RD $\|$ y axis and ND ||$z$ axis.

\section{Scanning precession electron diffraction}

A SPED correlation index map for region 1 is shown in Error! Reference source not found.a. The correlation index is a measure of the quality of matching between the experimental and theoretical diffraction patterns from template matching ${ }^{54}$ and can be used to visualise microstructural features analogous to band contrast maps produced from EBSD measurements (see experimental methods for more details on the SPED technique). The map is overlaid with monoclinic grain boundaries defined by a misorientation threshold of $5^{\circ}$ to emphasise the oxide microstructure and to enable grain size analysis. In region 1, the oxide grains are ordered and exhibit a uniform oxide microstructure with an average grain width of $\sim 57 \mathrm{~nm}$. In Fig. $4 \mathrm{~b}$ the SPED phase map from region 1 clearly shows that most of the oxide is composed of monoclinic $\mathrm{ZrO}_{2}$ with a minor tetragonal phase fraction in this region around $2 \%$ and a continuous layer of $\mathrm{ZrO}$ sub-oxide. Fig. 4cError! Reference source not found. shows the SPED orientation map of the monoclinic oxide formed in region 1, which is coloured according to deviation of the $\{10 \overline{6}\}_{\mathrm{m}-\mathrm{ZrO}_{2}}$ pole from the oxide growth direction. As shown in the frequency distribution in Fig. 4d, the SPED measured texture exhibits a larger spread compared with the EBSD measured data. The corresponding theoretical variants with a misorientation angle from the $\{10 \overline{6}\}_{\mathrm{m}-\mathrm{ZrO}_{2}}$ pole closest to zero are also plotted. The theoretical orientations are calculated based on the measured substrate orientation using the corresponding microscopy technique. The difference between the EBSD and the SPED 
measurements as well as between the experimental and the theoretically predicted orientations can be attributed to several factors: misalignment between the samples used in each technique, internal misorientations within the metal grain, misindexing of some SPED data and relative surface orientation before/after oxide removal. The SPED $\{10 \overline{6}\}_{\mathrm{m}-\mathrm{ZrO}_{2}}$ pole figure in Fig. 4d confirm the monoclinic texture measurement obtained using EBSD and again are overlaid with the orientations arising from the proposed theoretical orientation relationships. There is a strong alignment of the $\{10 \overline{6}\}_{\mathrm{m}-\mathrm{ZrO}_{2}}$ poles in the oxide growth direction, but with a larger spread from the theoretical orientation relationships due to the smaller number of investigated grains using SPED.
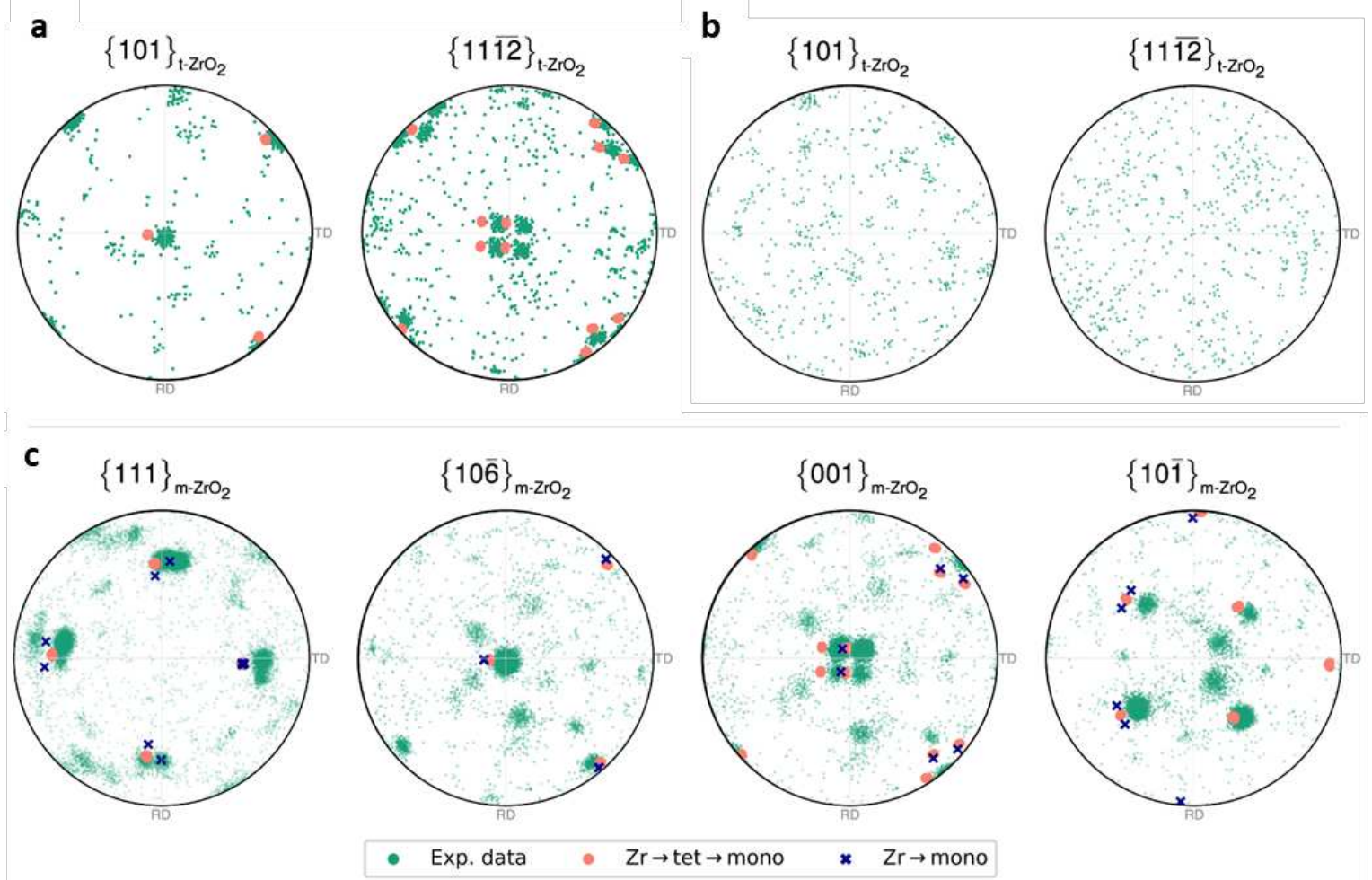

- Exp. data $\quad \mathrm{Zr} \rightarrow$ tet $\rightarrow$ mono $\quad$ × $\mathrm{Zr} \rightarrow$ mono
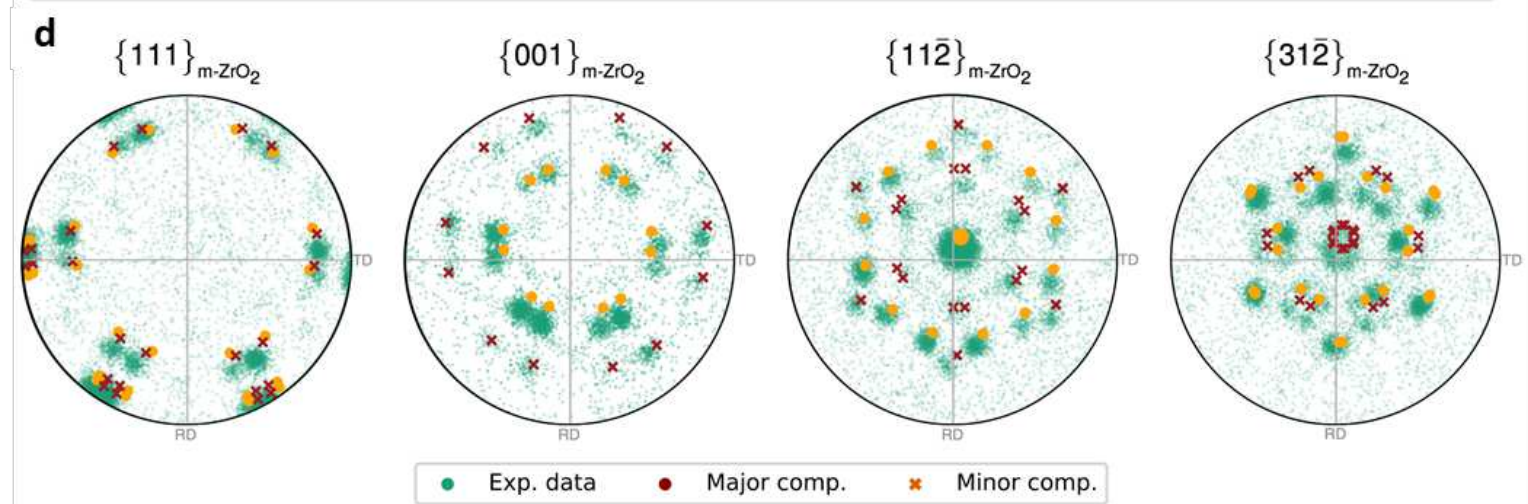

- Exp. data

- Major comp.

Fig. 3 EBSD and theoretical crystallographic orientation data. a, b Raw pole figures for equivalent poles $\{\mathbf{1 0 1}\}$ and $\{\mathbf{1 1} \overline{\mathbf{1 2}}\}$ of tetragonal $\mathrm{ZrO}_{2}$ in oxide region 1 (a) and 2 (b). c Raw pole figures of monoclinic $\mathrm{ZrO}_{2}$ for equivalent poles $\{\mathbf{1 1 1}\},\{\mathbf{1 0 6}\},\{\mathbf{0 0 1}\}$ and $\{\mathbf{1 0} \overline{\mathbf{1}}\}$ in oxide region 1. Denoted with pink disks and blue crosses are possible theoretical orientation relationships $\{\mathbf{1 1 1}\}<\mathbf{1 0 \overline { 1 }}>_{\mathbf{m}-\mathrm{ZrO}_{2}}\left\|\{\mathbf{1 0 1}\}<\mathbf{1 1} \overline{\mathbf{2}}>_{\mathrm{t}-\mathrm{ZrO}_{2}}\right\|\{\mathbf{0 0 0 2}\}<\mathbf{1 1} \overline{\mathbf{2}} \mathbf{0}>_{\mathrm{Zr}_{\mathbf{r}}}$ and $\{\mathbf{1 1 1}\}<\mathbf{1 0} \overline{\mathbf{1}}>_{\mathbf{m}-\mathbf{Z r O}_{2}} \|\{\mathbf{0 0 0 2}\}<\mathbf{1 1} \overline{\mathbf{2}} \mathbf{0}>_{\mathrm{Zr}}$, respectively. $\mathbf{d}$ Raw pole figures for equivalent poles $\{\mathbf{1 1 1}\},\{\mathbf{0 0 1}\},\{\mathbf{1 1} \overline{\mathbf{2}}\}$ and $\{\mathbf{3 1} \overline{\mathbf{2}}\}$ of monoclinic $\mathrm{ZrO}_{2}$ in oxide region 2 . 
276 Denoted with orange disks and red crosses are the major and minor theoretical orientation relationships $\{\mathbf{1 1} \overline{\mathbf{2}}\}<\mathbf{1 1 1}>_{\mathbf{m}-\mathbf{Z r O}_{\mathbf{2}}} \|\{\mathbf{0 0 0 2}\}<\mathbf{1 1 0 0}>_{\text {Zr }}$ and $\{\mathbf{3 1} \overline{\mathbf{2}}\}<$

$278 \mathbf{1 1 1}>_{\mathbf{m}-\mathrm{ZrO}_{\mathbf{2}}} \|\{\mathbf{0 0 0 2}\}<\mathbf{1 \mathbf { 1 0 0 }}>_{\mathrm{Zr}}$. All contoured pole figured are normalised to multiples of a random distribution (MRD) and oriented to be consistent with EBSD map in Fig. 1 with TD $\| \mathrm{x}$ axis, $\mathrm{RD} \| \mathrm{y}$ axis and ND $\| \mathrm{z}$ axis.
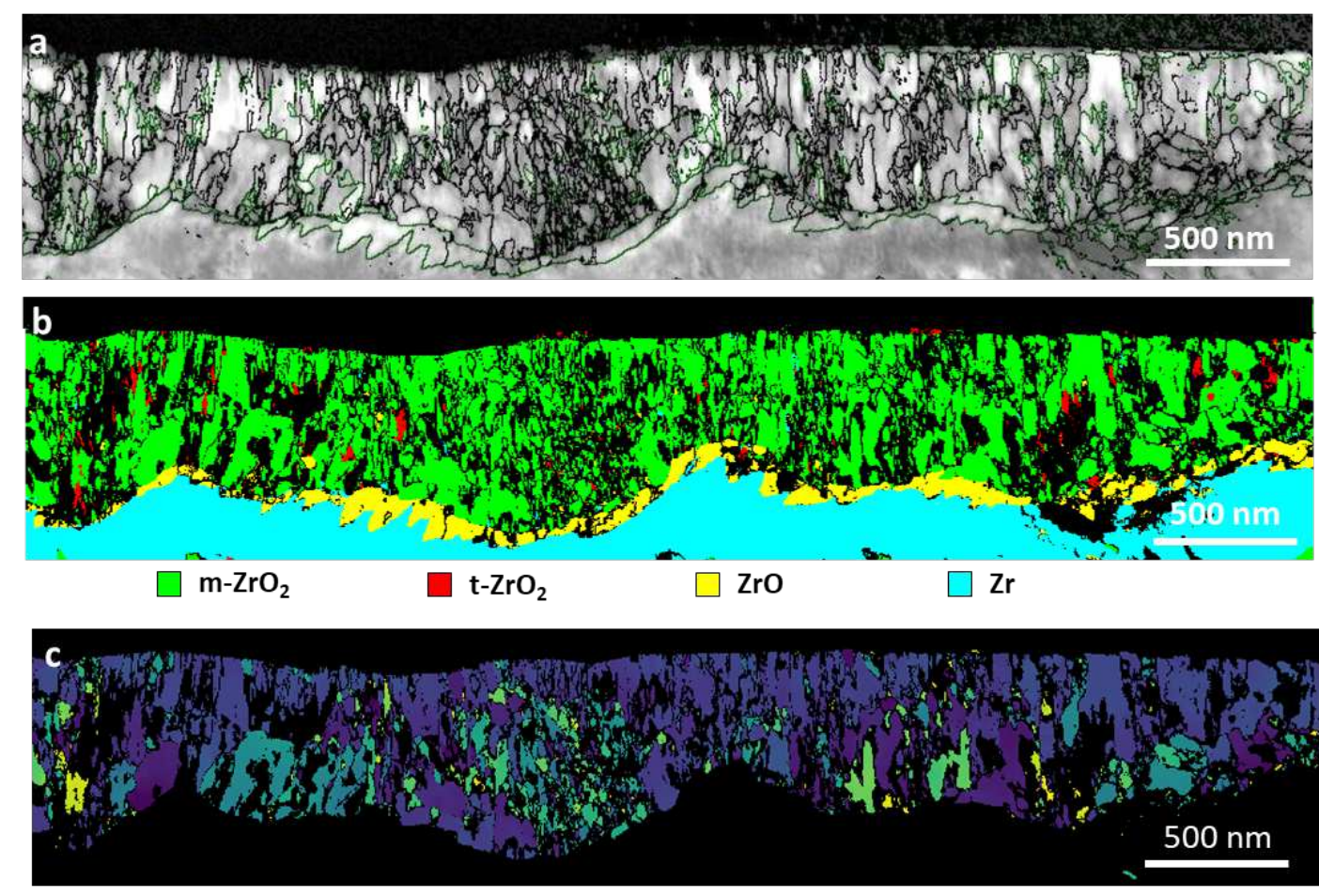

d

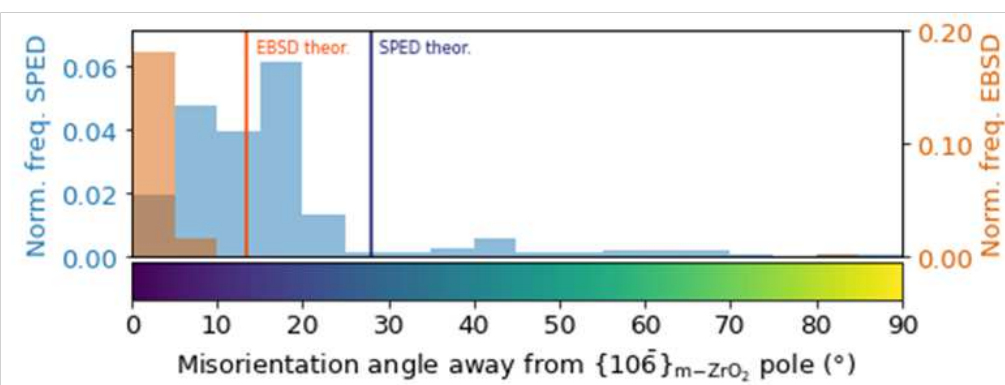

Fig. 4 Microstructure of oxide regions 1 using SPED. a Correlation index map with overlaid monoclinic oxide grain boundaries shown in black (interphase boundaries shown in green). b Phase map with phase reliability values less than 10 shown as non-indexed points coloured according to legend below (b). c Monoclinic $\mathrm{ZrO}_{2}$ orientation map coloured according to degrees away from the $\{\mathbf{1 0} \overline{\mathbf{6}}\}$ pole according to colour legend in $(\mathbf{d})$. $\mathbf{d}$ Normalised frequency of orientations and pole figure with respect to degrees away from the main texture component $\{\mathbf{1 0 6}\}_{\mathbf{m}-\mathbf{Z r o}_{\mathbf{2}}}$ for both EBSD and SPED data. Denoted with pink disks and blue crosses are possible theoretical orientation relationships $\{\mathbf{1 1 1}\}<$ $10 \overline{1}>_{\mathbf{m}-\mathrm{ZrO}_{2}}\left\|\{101\}<\mathbf{1 1 2}>_{\mathrm{t}_{-\mathrm{ZrO}_{2}}}\right\|\{0002\}<11 \overline{2} 0>_{\mathrm{Zr}}$ and $\{111\}<$ $\mathbf{1 0} \overline{\mathbf{1}}>_{\mathbf{m}-\mathrm{ZrO}_{\mathbf{2}}} \|\{\mathbf{0 0 0 2}\}<\mathbf{1 1 2} \mathbf{0}>_{\mathrm{Zr}}$, respectively. 

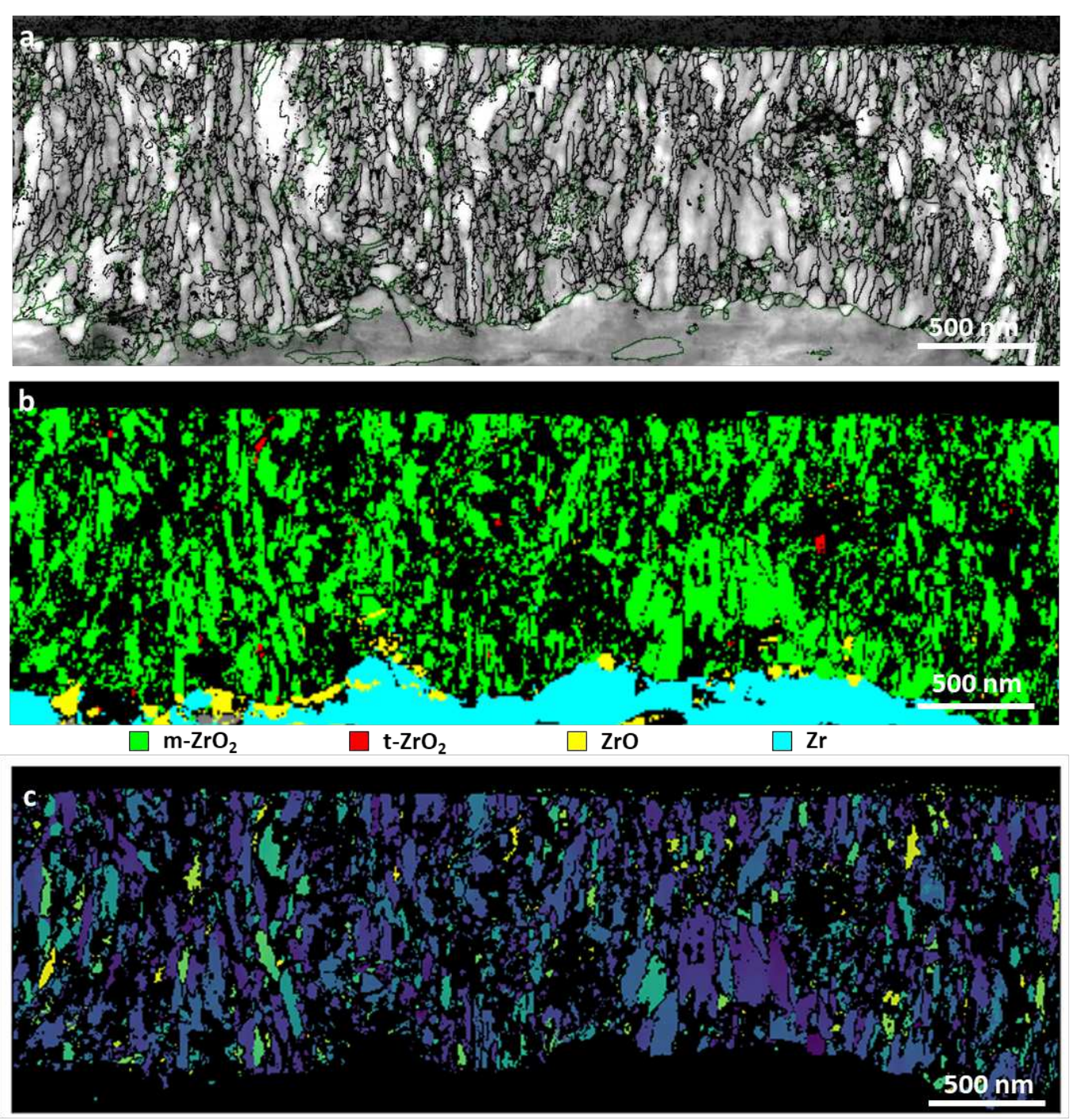

d

Fig. 5 Microstructure of oxide regions 2 using SPED. a Correlation index map with

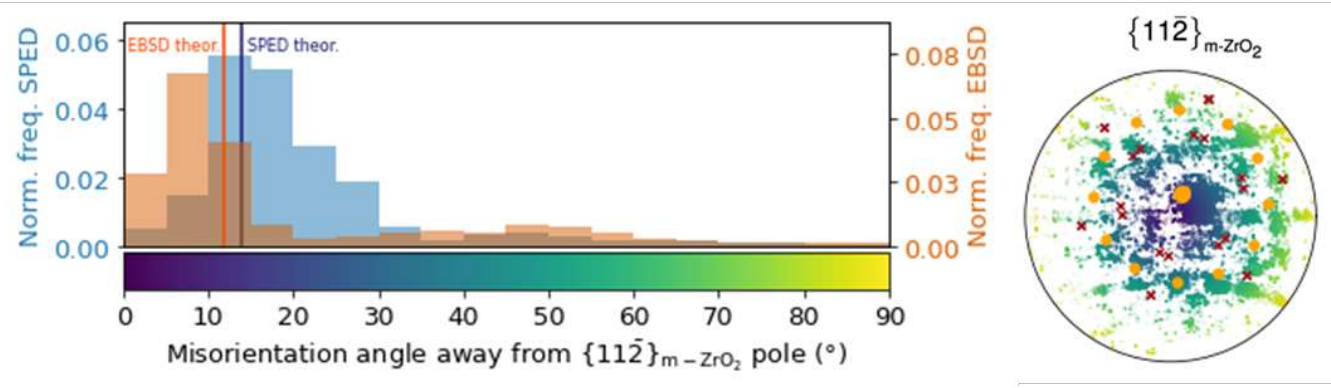
overlaid monoclinic oxide grain boundaries shown in black (interphase boundaries shown in green). b Phase map with phase reliability values less than 10 shown as non-indexed points coloured according to legend below (b). c Monoclinic $\mathrm{ZrO}_{2}$ orientation map coloured according to degrees away from the $\{\mathbf{1 1} \overline{2}\}$ pole according to colour legend in (d). d Normalised frequency of orientations and pole figure with respect to degrees away from the main texture component $\{\mathbf{1 1 2}\}_{\mathbf{m}-\mathbf{Z r O}_{\mathbf{2}}}$ for both EBSD and SPED data. Denoted with orange

300 disks and red crosses are the major and minor theoretical orientation $\{\mathbf{1 1} \overline{2}\}<$ $111>_{\mathbf{m}-\mathrm{ZrO}_{2}} \|\{0002\}<\mathbf{1 1 0 0}>_{\mathrm{Zr}}$ and $\{31 \overline{2}\}<111>_{\mathbf{m}-\mathrm{ZrO}_{2}} \|\{0002\}<\mathbf{1 1 0 0}>_{\mathrm{Zr}}$. 
Fig. 5a shows the SPED correlation index map from within region 2, where the oxide exhibits a complex microstructure consisting of narrow columnar grains and regions of equiaxed nanostructured oxide, with a smaller average grain width of $\sim 41 \mathrm{~nm}$ when compared to region 1. The SPED phase map in Fig. 5b shows that the majority of the oxide in this region is also composed of the monoclinic $\mathrm{ZrO}_{2}$ phase. The tetragonal phase fraction is less than $1 \%$ and is mainly confined to small, isolated equiaxed grains. There are also some isolated larger grains at the metal-oxide interface which are indexed as hexagonal $\mathrm{ZrO}$ suboxide phase in agreement with previous observations ${ }^{55}$. Fig. $5 \mathrm{c}$ and $\mathrm{d}$ show the $\mathrm{m}-\mathrm{ZrO}_{2}$ orientation map, coloured as degrees away from the $\{11 \overline{2}\}$ main texture component, and the corresponding normalised frequency of orientations compared with that from EBSD. Most of the monoclinic oxide grains are oriented between $0^{\circ}$ and $35^{\circ}$ away from the $\{11 \overline{2}\}$ pole with a peak of orientations at about $10^{\circ}$. As expected, the SPED data exhibits a larger spread compared to the EBSD data due to the smaller number of oxide grains sampled. The SPED $\{11 \overline{2}\}$ pole figure, also coloured as degrees away from the main texture component $\{11 \overline{2}\}$ and overlaid with the orientations from the theoretical orientation relationships calculated based on the orientation of the metal in the SPED data, confirm the presence of these two monoclinic texture components. We also observe a slightly larger misalignment between the experimental and the theoretical data compared to that in the EBSD measurement. The theoretical peaks of the $\{11 \overline{2}\}$ are very close to those obtained using both SPED and EBSD as seen in Fig. 5d.Error! Reference source not found. Additionally, the SPED technique allows us to investigate the potential role of the $\mathrm{ZrO}$ sub-oxide on the oxide texture. In region 1 , the suboxide forms an almost continuous layer between the metal substrate and the $\mathrm{ZrO}_{2}$ film, demonstrating the characteristic 'sawtooth' sub-oxide morphology ${ }^{55}$ as seen in Fig. $4 \mathrm{~b}$. On the other hand, fewer isolated grains were observed in region 2. Further analysis showed that an orientation relationship between the metal and the $\mathrm{ZrO}$ phase exists in region 1 but not in region 2. Fig. 6a shows the SPED orientation map coloured according to Euler angles for all major phases formed in region 1. The oxide has been split into subsets A, B and C in Fig. $6 \mathrm{a}$, which cover the three main sub-oxide orientations observed in this region. Contoured $\{0002\}$ and $<\overline{2} 110>$ pole figures for the $\mathrm{Zr}$ substrate and $\{\overline{1} 011\}$ and $<10 \overline{1} 2>$ pole figures for the different $\mathrm{ZrO}$ sub-oxide regions are shown in Fig. 6b-e, where the substrate $\{0002\}$ pole is aligned with the ' $z$ ' direction of the pole figure in order to better visualise any orientation relationships. The pole figures show that in subset $\mathrm{A}$ and $\mathrm{B}$, the sub-oxide follows the main orientation relationship identified in ${ }^{56}$, with $\{0002\}_{\mathrm{Zr}} \|\{1011\}_{\mathrm{ZrO}}$ and $<\overline{2} 110>_{\text {Zr }} \|<10 \overline{1} 2>_{\text {Zro }}$. This is also in agreement with TEM observations of sub-oxide formation during in-situ annealing ${ }^{57}$. In subset $\mathrm{C}$, the orientation relationship is less clear, as this region is composed of two distinct sub-oxide orientations, however both of them are also close to the major orientation relationship reported previously ${ }^{56,57}$. 

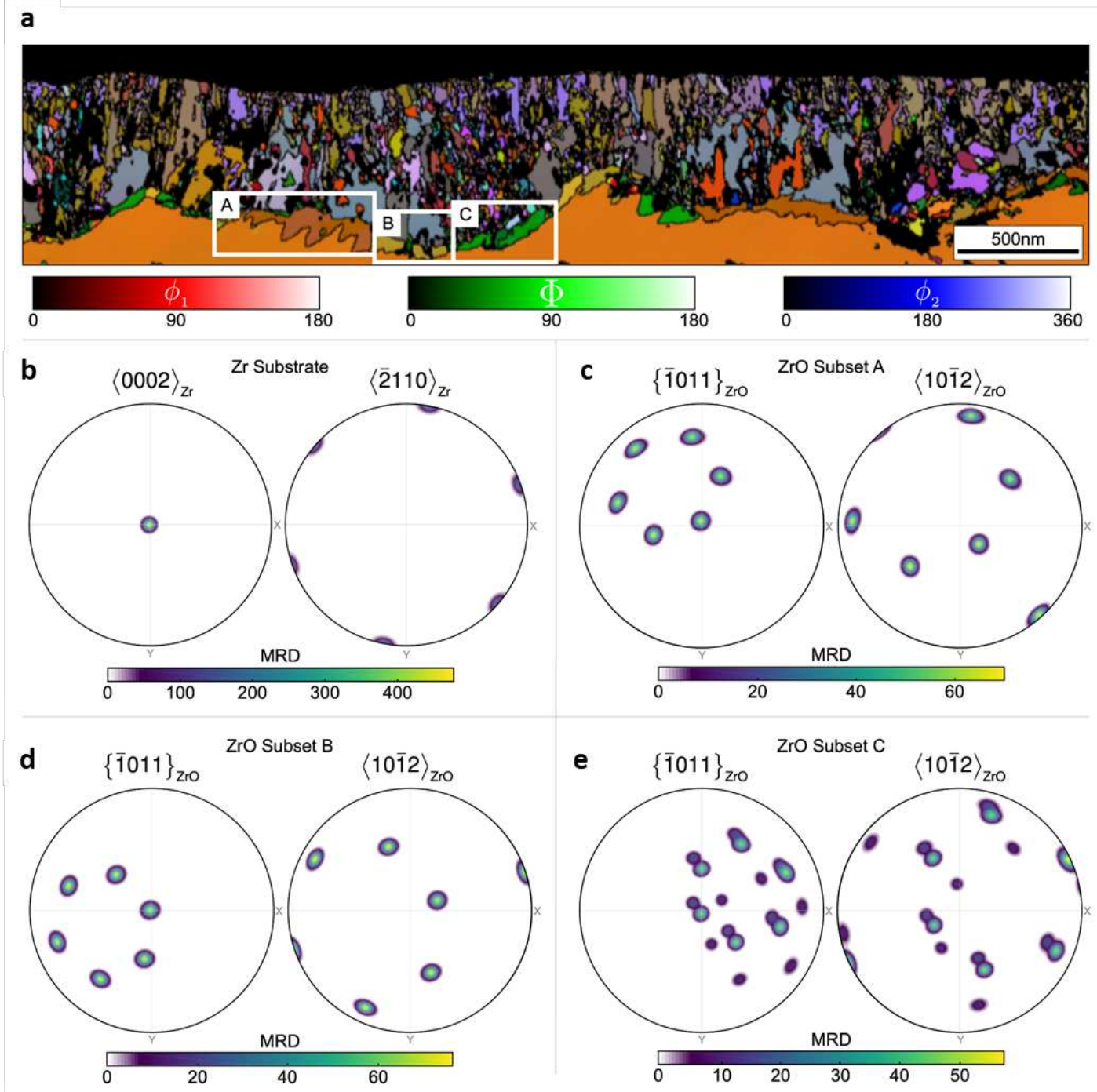

Fig. 6 Sub-oxide orientation in oxide region 1. a SPED orientation map for hexagonal $\mathrm{ZrO}$ and hexagonal $\mathrm{Zr}$ from region 1 in Euler angle colouring as shown in legend. $\mathbf{b}$ Contoured $\{\mathbf{0 0 0 2}\}$ and $\langle\overline{\mathbf{2}} \mathbf{1 1 0}>$ pole figures for the Zr substrate. c-e Contoured $\{\overline{\mathbf{1 0 1 1}}\}$ and $<\mathbf{1 0 1 2}>$ pole figures for the different $\mathrm{ZrO}$ sub-oxide subsets labelled in (a). The $\{\mathbf{0 0 0 2}\}_{\mathrm{Zr}}$ is aligned parallel to the pole figure $\mathrm{z}$ direction to make orientation relationships clearer.

\section{Discussion}

347 Detailed analysis over significant length scales shows that the orientation of Zr metal grains 348 has a dramatic effect on the subsequent development of the local oxide nanostructure and texture, and thus the local protectiveness of the oxide. This has wide-reaching implications for the understanding of oxide nucleation and growth processes, and also highlights the importance of multiscale characterisation and correlative microscopy in understanding these complex processes. In the present case, focusing on two oxide regions separated by about 10 $\mathrm{mm}$, identical material and corrosion conditions resulted in marked differences in oxide protectiveness, which seems to be strongly correlated to differences in the orientation of the underlying metal grains. Our findings contradict the common belief that in single-phase $\mathrm{Zr}$ alloys with split-basal texture, substrate orientation has little influence on the oxide texture ${ }^{31}$. 

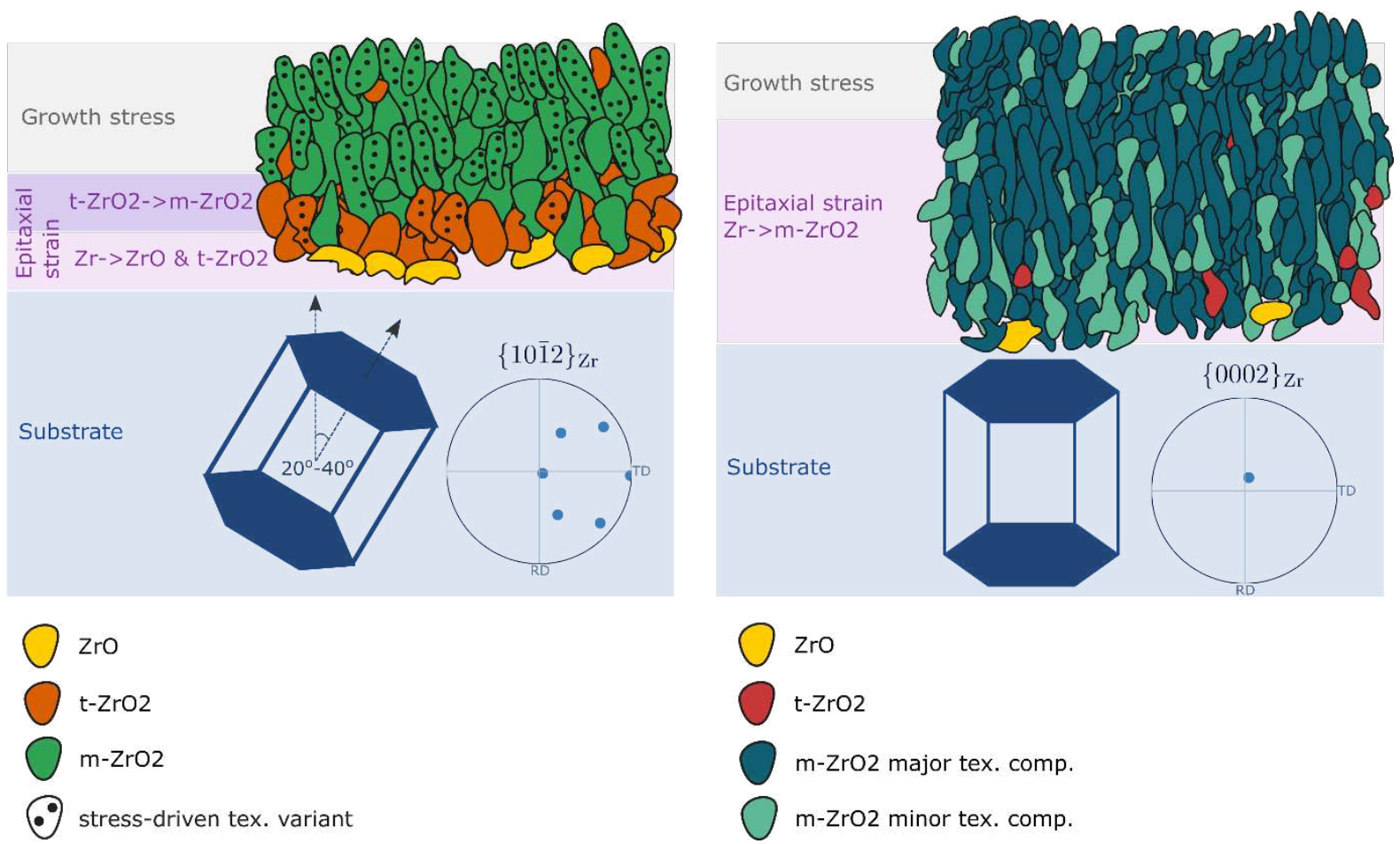

Fig. 7. Schematic representation of the mechanisms of $\mathrm{Zr}$ metal to oxide transformation and their effect on the grain morphology and texture of the oxide film based on the orientation of the substrate metal grain. Two types of oxide microstructure are observed based on the orientation of the substrate grain. a Region 1: a protective oxide layer with long columnar grains and low energy grain boundaries under the influence of the growth stress. $\mathbf{b}$ Region 2: less protective oxide, thicker and with more disordered smaller grains. In (a) $\mathrm{ZrO}$, $\mathrm{t}-\mathrm{ZrO}_{2}$ and $\mathrm{m}-\mathrm{ZrO}_{2}$ grains are shown in yellow, orange and green, respectively, and dots indicate stress-driven texture variant; in (b) $\mathrm{ZrO}, \mathrm{t}-\mathrm{ZrO}_{2}$ and $\mathrm{m}-\mathrm{ZrO}_{2}$ grains are shown in yellow, orange and green, respectively, where darker and lighter shade of green indicates the major and minor $\mathrm{m}-\mathrm{ZrO}_{2}$ texture components.

The schematic in Fig. 7 summarises our findings for the competing mechanisms of oxide nucleation and growth. In a typical metal grain in split-basal textured single-phase $\mathrm{Zr}$ alloys, the c-axis of the hep crystal is positioned at $20^{\circ}$ to $40^{\circ}$ away from the outer surface normal, and so pyramidal planes with Miller indices $\{h 0 i l\}$ are close to parallel to the outer surface (Fig. 7a). In contrast, these alloys also contain a smaller fraction of grains with basal planes close to parallel to the outer surface, represented in Fig. 7b. According to our observations, the former substrate grain type forms a thinner oxide film with wider and more columnar grains, with higher fraction of metastable $\mathrm{ZrO}$ and tetragonal $\mathrm{ZrO}_{2}$ phases, compared to the latter. In both cases, the majority of the oxide consists of monoclinic $\mathrm{ZrO}_{2}$, however, with a strong one-component epitaxial texture in the first case, and a twocomponent epitaxial texture in the second case.

We now discuss how the crystallographic orientation of the metal grain influences the formation of these oxide microstructures. Since the basal plane is the most densely packed and the lowest energy plane in the hcp $\mathrm{Zr}$ lattice, it is expected to be the most corrosion resistant. The pyramidal plane $\{h 0 i l\}$ orientations are expected to exhibit properties in between those of the basal and the prism orientations as they lie on an energetically favoured region in the surface energy anisotropy projection with a minimum at the basal orientation $\{0002\}$ and a maximum at the prism orientation $\{10 \overline{1} 0\}$, as calculated by a broken-bond 
based geometric model ${ }^{58}$. Multiple experimental and theoretical studies ${ }^{7,23,59}$ on single crystal $\mathrm{Zr}$ have shown that the prismatic planes oxidise more readily in water and in pure oxygen than the basal plane with an estimated oxygen diffusion twice as fast along the [1010] direction compared to the [0002] direction. Nevertheless, based on our FIB cross section analysis, the 'split-basal' orientations showed a corrosion rate two times lower than that of the basal-type orientations. A similar result was reported for $\mathrm{Ni}^{12,14}$, where under certain thermodynamic conditions, the corrosion rate did not follow the surface energy anisotropy of face-centred cubic metals. Instead, the formation of a passivating oxide film slowed down the corrosion rate on certain surfaces, and the surfaces most susceptible to corrosion were found to be those most able to form a protective film ${ }^{12}$. In the present case, that effect can be attributed to the competition between the epitaxial strain, i.e. the lattice matching, and the growth stress in the nucleation and growth stages of oxide formation. A charge-optimized many-body potential study by Noordhoek et al. ${ }^{26}$ demonstrated that water dissociates faster, and that atomic $\mathrm{O}$ and $\mathrm{H}$ diffuse further into the prism planes with a more even distribution compared with the basal plane - $87 \%$ of $\mathrm{O}$ was found to lie between the top two layers for $\{0002\}$, compared to $54 \%$ and $44 \%$ for $\{11 \overline{2} 0\}$ and $\{10 \overline{1} 0\}$, respectively. Therefore, oxygen atoms will be more evenly distributed and penetrate to a greater depth in substrate orientations close to the ideal split-basal texture, such as that in region 1. That would lead to a higher fraction of oxygen vacancies in the same volume of material, and hence, favour the formation of the lower-stoichiometry $\mathrm{ZrO}$ phase and the vacancy-stabilised tetragonal $\mathrm{ZrO}_{2}$ phase, when compared with the basal orientation that corresponds to region 2.

Both types of Zr grains oxidise by strong alignment of the child oxide phase with the parent metal phase according to specific epitaxial orientation relationships. In the case of a grain with a 'split-basal' orientation, it was previously thought that no single orientation relationship exists between the metal and the oxide ${ }^{31}$. We identified for the first time that the orientation of the metal grain energetically favours the nucleation of tetragonal $\mathrm{ZrO}_{2}$ based on the epitaxial relationship $\{101\}<11 \overline{2}>_{\mathrm{t}^{-} \mathrm{ZrO}_{2}} \|\{0002\}<11 \overline{2} 0>_{\mathrm{Zr}}$, and in some cases hexagonal ZrO based on the epitaxial relationship $\{\overline{1} 011\}<10 \overline{1} 2>_{\text {Zro }} \|\{0002\}<$ $11 \overline{2} 0>_{\mathrm{Zr}}$. And so, when the sub-oxide $\mathrm{ZrO}$ phase does form, it can transform to tetragonal $\mathrm{ZrO}_{2}$, maintaining the same tetragonal texture as that of the grains directly nucleated from the $\mathrm{Zr}$ metal. Lattice matching also drives the tetragonal to monoclinic phase transformation based on the relationship $\{111\}<10 \overline{1}>_{\mathrm{m}-\mathrm{ZrO}_{2}} \|\{101\}<11 \overline{2}>_{\mathrm{t}-\mathrm{ZrO}_{2}}$. We note that these three orientation relationships can be combined as $\{111\}<10 \overline{1}>_{\mathrm{m}-\mathrm{ZrO}_{2}} \|\{101\}<$ $11 \overline{2}>_{\mathrm{t}-\mathrm{ZrO}_{2}}\left\|\{\overline{1} 011\}<10 \overline{1} 2>_{\mathrm{ZrO}}\right\|\{0002\}<11 \overline{2} 0>_{\mathrm{Zr}}$. In contrast, we have shown that a $\mathrm{Zr}$ metal grain with the c-axis normal to the interface, is more likely to directly nucleate as monoclinic $\mathrm{ZrO}_{2}$, with $<111>_{\mathrm{m}-\mathrm{ZrO}_{2}} \|<1 \overline{1} 00>_{\mathrm{Zr}}$ and $\{11 \overline{2}\}_{\mathrm{m}-\mathrm{ZrO}_{2}} \|\{0002\}_{\mathrm{Zr}}$ or $\{31 \overline{2}\}_{\mathrm{m}-\mathrm{ZrO}_{2}} \|\{0002\}_{\mathrm{Zr}}$.

Fig. 8 shows the atomic structures of the interfaces between the metal and oxide phases in the two types of regions, and Table 1 lists the epitaxial strains required between phase transformations, calculated according to the $\mathrm{Zr}-\mathrm{Zr}$ distance within the corresponding crystal structure. We note that there is no significant difference in the total epitaxial strains in the two regions when we consider the transformations from $\mathrm{Zr}$ metal to monoclinic $\mathrm{ZrO}_{2}$. Therefore, we need to consider the effect of growth stresses on the oxidation process, which is determined by a combination of the effect of areal footprint of the symmetry variant and the crystal stiffness anisotropy of the child phase ${ }^{29,35}$. The child phase variants formed from 
different parent symmetry operators will have different areal footprints on the outer surface to ND, the symmetry variants would have the same footprint, whereas when it is positioned at an angle to ND, these will differ. The epitaxial strains necessary to form a coherent interface between the two lattices, on the other hand, would stay the same - the atomic interface is the same but rotated with respect to the global (sample) coordinate system. And so, in region 1, we would have an inequivalent distribution of areal footprints and stiffnesses, some of which will be favourable for growth based on minimising the stresses and with most of the volume change accommodated normal to the metal-oxide interface ${ }^{36}$. On the other hand, in region 2, the epitaxial strains remain strong and drive all symmetry variants to grow in equal proportion.

a

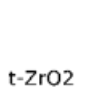

$\mathrm{t}-\mathrm{ZrO} 2$

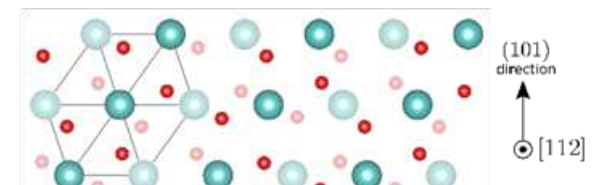

h-Zro

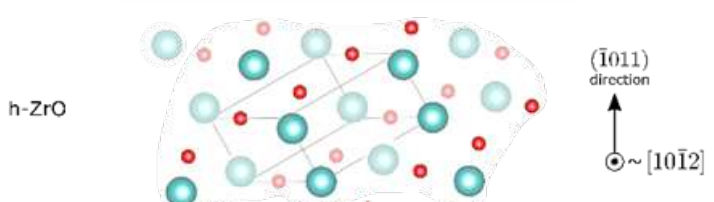

hcp-Zr
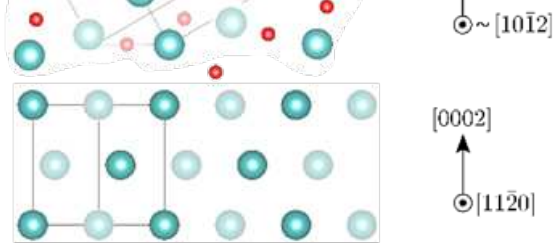

hcp-Zr

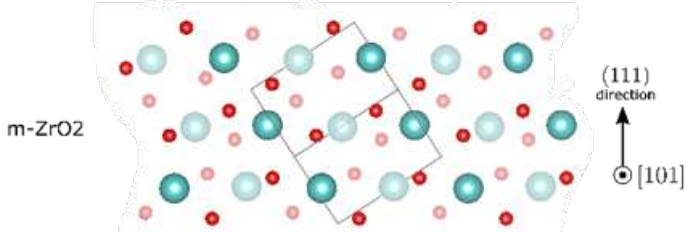

$\mathrm{t}-\mathrm{ZrO} 2$
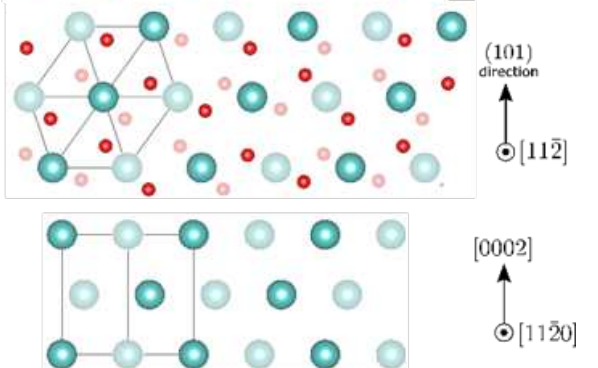

b

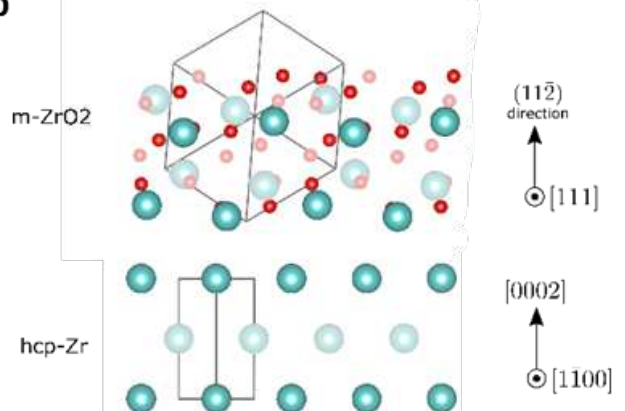

Fig. 8. Atomic structure of interface. Schematic of the interfaces formed based on the identified orientation relationships. a Region 1: $\{101\}<11 \overline{2}>_{\mathrm{t}-\mathrm{ZrO}_{2}} \|\{\overline{1} 011\}<$ $10 \overline{1} 2>_{\text {Zro }} \|\{0002\}<11 \overline{2} 0>_{\mathrm{Zr}}$ (left) and $\{111\}<10 \overline{1}>_{\mathrm{m}-\mathrm{ZrO}_{2}} \|\{101\}<$ $11 \overline{2}>_{\mathrm{t}-\mathrm{ZrO}_{2}} \|\{0002\}<11 \overline{2} 0>_{\mathrm{Zr}}$ (right). b Region 2: $\{11 \overline{2}\}<111>_{\mathrm{m}-\mathrm{ZrO}_{2}} \|\{0002\}<$ $1 \overline{1} 00>_{\mathrm{Zr}}$. Two atomic planes shown in the out-of-page direction, where shade indicates the atom's relative distance and darker atoms are closer to the reader. Blue and red spheres represent $\mathrm{Zr}$ and $\mathrm{O}$ atoms, respectively. Produced using VESTA ${ }^{60}$.

Based on the epitaxial relationships in region 1, the nucleated tetragonal variants will have either the $\{001\}$ or the $\{110\}$ plane close to parallel to the outer surface, which then transform to $\{10 \overline{6}\}$ and $\{100\}$ in the monoclinic phase, respectively. Previously, preferential growth of the $\{001\}_{\mathrm{t}-\mathrm{ZrO}_{2}}$ and the $\{10 \overline{6}\}_{\mathrm{m}-\mathrm{ZrO}_{2}}$ was attributed to their small areal footprint 
as a determining factor that minimises the compressive stress ${ }^{29}$. However, these orientations have very similar areal footprints $-26.0 \AA^{2}$ and $26.4 \AA^{2}$ for $\{001\}_{\mathrm{t}-\mathrm{ZrO}_{2}}$ and $\{110\}_{\mathrm{t}-\mathrm{ZrO}_{2}}$, and $27.3 \AA^{2}$ and $27.9 \AA^{2}$ for $\{10 \overline{6}\}_{\mathrm{m}-\mathrm{ZrO}_{2}}$ and $\{100\}_{\mathrm{m}-\mathrm{ZrO}_{2}}$, respectively. Error! Reference source not found.a shows the directional dependence of Young's modulus in the bodycentred tetragonal $\mathrm{ZrO}_{2}$ crystal, which suggests the $\{001\}_{\mathrm{t}-\mathrm{ZrO}_{2}}$ has a lower stiffness compared to $\{110\}_{\mathrm{t}-\mathrm{ZrO}_{2}}$. Thus, the growth of the $\{001\}_{\mathrm{t}-\mathrm{ZrO}_{2}}$ variants, which subsequently transform to $\{10 \overline{6}\}_{\mathrm{m}-\mathrm{ZrO}_{2}}$, would minimise the growth stress in the oxide film. These results agree with previous studies, which have reported similar monoclinic oxide textures of $\{10 \bar{l}\}$ (where $l=2,3,4)^{61-64}$. The particular value of $l$ will depend on the metal grain orientation that the oxide has transformed from. Importantly, our results show that the tetragonal phase is a required precursor to the monoclinic phase, in order for a protective oxide layer to form with a strong single-footprint epitaxial texture consisting of wider and more columnar grains. The sub-oxide was found not to influence the oxidation significantly and is therefore more likely a byproduct of slow oxidation, as suggested previously ${ }^{47,65}$. These stronger textured oxides are likely to have a higher fraction of protective, low angle grain boundaries, and also coarser, more coherent microstructures as it was previously shown that columnar grain growth is terminated by small mismatches between local grain orientations ${ }^{66}$.

In contrast to our findings, the tetragonal to monoclinic phase transformation was thought previously to cause cracking in the oxide layer, and thus have a mainly negative role on the oxidation process ${ }^{34}$. We need to point out that there are different mechanisms of tetragonal phase stabilisation - chemically stabilised grains due to alloying elements such as $\mathrm{Sn}$, and stress stabilised grains might be allowed to grow larger and therefore destabilise the oxide when they transform. Tetragonal grains stabilised throughout the oxidation process, whether due to small size or vacancies, are likely to have a beneficial effect by allowing for the formation a coherent and protective microstructure. Another potential contributing factor to the more protective oxide in region 1 is that the metastable phases allow a more gradual volume expansion from metal to oxide, and so fewer defects develop in the oxide microstructure leading to lower local corrosion rates. The volume strain necessary to transform $\mathrm{Zr}$ to $\mathrm{ZrO}$ is $11.9 \%$, the strain to transform $\mathrm{ZrO}$ to tetragonal $\mathrm{ZrO}_{2}$ is $29.3 \%$ and the expansion from tetragonal to monoclinic $\mathrm{ZrO}_{2}$ is $5.9 \%$, as opposed to a sudden expansion of $53.3 \%$ from $\mathrm{Zr}$ to monoclinic $\mathrm{ZrO}_{2}$, as occurs in region 2 .

Both orientation relationships in region 2 form an oxide with a single unique areal footprint - the $\{11 \overline{2}\}_{\mathrm{m}-\mathrm{ZrO}_{2}}$ with a footprint of $31.5 \AA^{2}$ or the $\{31 \overline{2}\}_{\mathrm{m}-\mathrm{ZrO}_{2}}$ plane with a footprint of $32.1 \AA^{2}$, since they are both formed from a metal grain with the basal plane normal to the oxide growth direction. The similar footprints, and potentially similar stiffnesses of the two orientations, leads to the epitaxial strain, rather than the growth stress, being the stronger mechanism, driving the growth of both texture components with a higher prevalence of the $\{112\}_{\mathrm{m}-\mathrm{ZrO}_{2}}$ orientation. It is the simultaneous growth of two epitaxial texture components in combination with the direct transformation from $\mathrm{Zr}$ metal to monoclinic $\mathrm{ZrO}_{2}$ that most likely enhances oxygen ion transport through the oxide as the elongated oxide grains are not so well organised and more high-angle grain boundaries are formed reducing the level of passivation.

Table 1. Epitaxial strains. Calculated based on the difference between the $\mathrm{Zr}-\mathrm{Zr}$ distances in the corresponding lattices. Shear is ignored. 


\begin{tabular}{|c|c|c|c|c|}
\hline & $\begin{array}{l}\text { Phase } \\
\text { transformation }\end{array}$ & $\begin{array}{l}\text { In-plane } \\
\text { strains (\%) }\end{array}$ & $\begin{array}{l}\text { Average in- } \\
\text { plane strain (\%) }\end{array}$ & $\begin{array}{l}\text { Average out-of- } \\
\text { plane strain (\%) }\end{array}$ \\
\hline \multirow{4}{*}{ 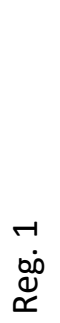 } & hcp-Zr -> h-ZrO & $6.6,-5.4$ & 0.6 & 0.6 \\
\hline & hcp-Zr ->t-ZrO & $10.1,11.0$ & 10.6 & 12.0 \\
\hline & $\mathrm{h}-\mathrm{ZrO}->\mathrm{t}-\mathrm{ZrO}_{2}$ & $3.8,15.5$ & 9.7 & 11.5 \\
\hline & $\mathrm{t}-\mathrm{ZrO}_{2}->\mathrm{m}-\mathrm{ZrO}_{2}$ & - & 1.4 & -0.6 \\
\hline 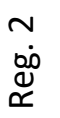 & hcp-Zr $->\mathrm{m}-\mathrm{ZrO}_{2}$ & - & 11.8 & 11.5 \\
\hline
\end{tabular}

a

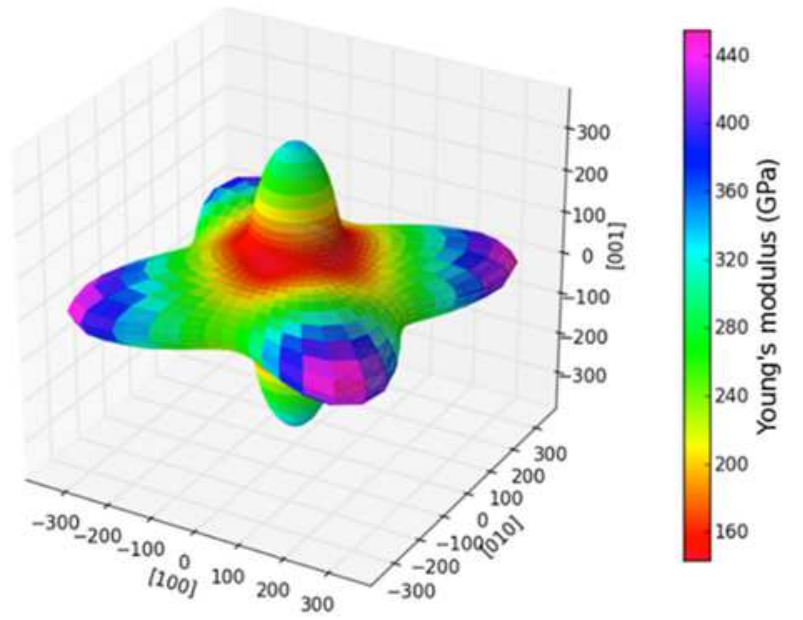

b
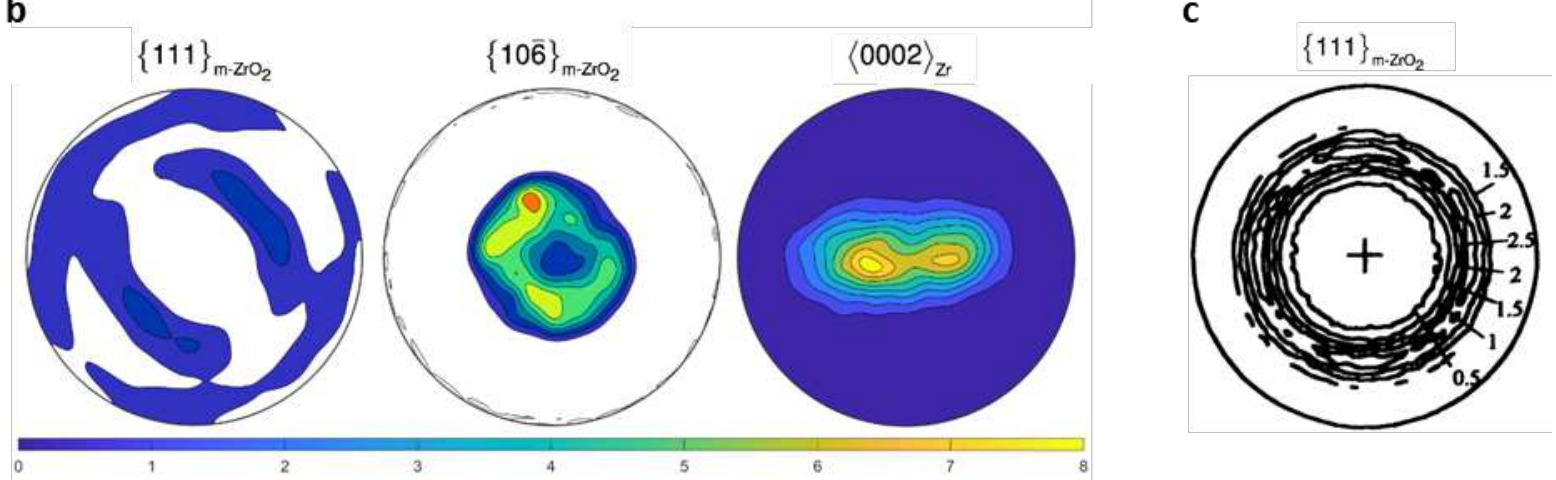

Fig. 9 Young's modulus of $\mathrm{t}-\mathrm{ZrO}_{2}$ and modelled macrotexture. a Directional dependence of Young's modulus in the body-centred tetragonal $\mathrm{ZrO}_{2}$ crystal. b Contoured pole figures for the $\{111\}$ and $\{10 \overline{6}\}$ monoclinic $\mathrm{ZrO}_{2}$ poles as modelled using the orientation relationships obtained in this study based on Zircaloy-4 substrate with EBSD texture shown in the $\{0002\}$ $\mathrm{Zr}$ contour pole figure. c Measured monoclinic $\mathrm{ZrO}_{2}\{111\}$ contour pole figure from a $14 \mu \mathrm{m}$ thick oxide film formed in $400^{\circ}$ steam on Zircaloy- 4 by Parise ${ }^{67}$.

Moreover, we considered the oxide texture that would result due to a transformation of a large number of metal grains present in a typical sample with split-basal texture. The results are shown in Error! Reference source not found., where all metal orientations with a basal 
pole within $20^{\circ}$ of ND were assumed to transform according to the orientation relationships in region 2, and the remaining metal orientations were assumed to transform according to the orientation relationships in region 1 with a preferential growth of the oxide orientations closest to $\{10 \overline{6}\}_{\mathrm{m}-\mathrm{ZrO}_{2}}$. The monoclinic oxide $\{111\}$ contour pole figure shows a close to uniform distribution, which agrees well with the measured $\{111\}$ pole figure by Parise ${ }^{67}$ in Error! Reference source not found. (B). Combined with the result for the $\{10 \overline{6}\}_{\mathrm{m}-\mathrm{ZrO}_{2}}$ pole figure, it can be seen how the macrotexture of the oxide appears to have a preferential fibre. However, this macrotexture is formed by a large number of epitaxial textured oxide grains formed from metal grains with different orientations. Our study demonstrates that there is a clear epitaxial orientation relationship determining the oxide orientations, and it is incorrect to describe the oxide crystallographic texture as 'fibre' texture.

In summary, this work demonstrates the importance of the substrate orientation on the corrosion protectiveness of the oxide and the complex interplay between the two mechanisms of epitaxial strain and growth stress on that process. In engineering alloys, which experience inward corrosion and a Pilling-Bedworth ratio of more than one, epitaxial strain due to a lattice matching between the substrate and the oxide drives a more disorderly growth of the nanostructure oxide and therefore less protection. The growth stress, on the other hand, achieves a more well-ordered, coarser oxide microstructure and improved global corrosion performance. This finding opens the possibility for improved corrosion performance of a large range of alloys through optimisation of their processing route.

\section{Methods}

\section{Material selection}

The material used in this study was sheet Zircaloy-2 material in the recrystallised condition with average equiaxed grain diameter of $\sim 35.9 \mu \mathrm{m}$ and chemical composition within the range defined in ASTM B353. The coupon was subjected to corrosion testing for 46 days at $350^{\circ} \mathrm{C}$ in simulated pressurised water reactor (PWR) chemistry as part of a large-scale testing program ${ }^{68}$, forming an average oxide thickness of $\sim 1.2 \mu \mathrm{m}$ as estimated from weight gain data.

\section{Sample Preparation}

In order to reduce the topography inherent to oxidised zirconium alloys and to remove the outer portion of equiaxed grains related to the fast initial oxidation process ${ }^{39}$, a $2 \times 2 \mathrm{~mm}$ section of the oxidised Zircaloy-2 sample was prepared using 4000 grit silicon carbide paper with a final polish in $0.06 \mu \mathrm{m}$ colloidal silica. A total of $\sim 0.4 \mu \mathrm{m}$ of oxide was removed, as measured by subsequent cross-sectional measurements. EBSD analysis was performed on this surface as discussed below. Following EBSD analysis, two TEM liftouts were made from different areas of the prepared oxide surface using the in situ liftout technique with an FEI Quanta 3D focused ion beam (FIB) instrument. These samples were thinned to electron transparency for SPED analysis using the standard FIB procedure with a final low energy cleaning step. The position of these liftouts is shown in Fig. $1 \mathrm{~b}$.

In order to evaluate the local oxide thickness, trenches were prepared in different oxide regions using the same FIB instrument. The oxide surface was firstly protected using Pt, a regular cross section pattern was then used to mill out a region of the oxide and underlying metal using an accelerating voltage of $30 \mathrm{KeV}$ and a current of $3 \mathrm{nA}$. A final polish was performed on the cross-sectional surface at $1 \mathrm{nA}$ in order to provide a clean surface for 
accurate oxide thickness measurement. Secondary electron imaging was performed at $5 \mathrm{KeV}$ with a current of $1.6 \mathrm{nA}$.

The remaining oxide was then carefully removed using $0.06 \mu \mathrm{m}$ colloidal silica. The material removal rate was relatively slow to ensure that significant amounts of the $\mathrm{Zr}$ substrate were not removed. Once the oxide was removed, the underlying metal microstructure was assessed with a further EBSD map (details below), using trenches as fiducial markers to match the metal and oxide locations.

\section{Electron backscatter diffraction}

In order to obtain reliable bulk EBSD analysis of nanograined materials such as $\mathrm{ZrO}_{2}$, it is vital that the interaction volume of the electron beam is minimised. In the present case this is achieved with a low accelerating voltage of $10 \mathrm{KeV}$ and a current of $1.6 \mathrm{nA}$ using an FEI Magellan 400 XHR Field Emission Gun Scanning Electron Microscope (FEG-SEM). The unique column design on this microscope allows for a high current density to be maintained in a small spot size in order to get sufficient signal out of the sample at low accelerating voltages/currents. The disadvantage of using such beam conditions is that the backscatter signal on the detector is relatively weak. This is overcome by the use of the high-resolution Oxford Instruments Nordlys Nano 2 EBSD detector, operated at $\sim 7 \mathrm{~Hz}$, using $4 \mathrm{x} 4$ binning. For the oxide measurement, a total area of $50 \times 50 \mu \mathrm{m}^{2}$ was measured with a step size of 100 $\mathrm{nm}$, with a total acquisition time of $\sim 24$ hours. The patterns were indexed using the Oxford Instruments Aztec software suite with an indexing rate of $\sim 60 \%$. Due to the small oxide grain size, each indexed point in the map most likely corresponds to a unique oxide grain. It should be pointed out here that there are small $\sim 5 \mu \mathrm{m}$ squares in the orientation map that appear to show a different crystallographic texture. These are regions of intentional focusedion-beam (FIB) damage that formed part of another study ${ }^{49}$, and are excluded from this analysis.

After oxide removal, a second EBSD map was obtained from the underlying metal. Due to the relatively large grain size, an accelerating voltage of $30 \mathrm{keV}$ was used with a current of $3.2 \mathrm{nA}$ using the same microscope and detector set up as used for the oxide EBSD. Patterns were acquired with $8 \times 8$ binning over a total area of $100 \times 100 \mu \mathrm{m}$. A $250 \mathrm{~nm}$ step size was used at a speed of $\sim 70 \mathrm{~Hz}$ giving a total acquisition time of 40 minutes. As with the oxide map, the patterns were indexed using the Oxford Instruments Aztec software suite with an indexing rate of $\sim 80 \%$. All EBSD data was analysed using the Channel 5 software suite developed by Oxford Instruments and the open-source MATLAB toolbox MTEX ${ }^{69}$. A similar number of indexed points in all regions were analysed for a more accurate texture comparison.

\section{Scanning precession electron diffraction}

In order to analyse the local microstructure and microtexture in different oxide regions in more detail, scanning precession electron diffraction was performed on the two FIB liftouts from regions 1 and 4 in Fig. 1 (B). SPED phase and orientation maps were acquired using a Tecnai TF30 transmission electron microscope operated at $300 \mathrm{KeV}$ fitted with a Nanomegas ASTAR SPED system. The patterns were acquired at 25 frames per second with a step size of $5 \mathrm{~nm}$ and a precession angle of 0.4 degrees and indexed offline using the ASTAR template matching procedure ${ }^{54}$. Orientations and phases identified with a reliability index less than 10 were excluded from the analysis, more details on these criteria can be found in ref. ${ }^{70}$. The grain size is estimated using the linear intercept method from the resultant grain boundary maps, with grain boundaries defined by a critical misorientation threshold of $5^{\circ}$. Although the 
analysis of the entire oxide thickness is not possible due to removal of the outer portion of oxide, an accurate measurement of the grain widths in the inner oxide can be performed.

\section{Oxide texture modelling}

A Python code was developed in order to model the oxide texture formed on the observed substrate orientations. The raw EBSD orientation data was used to find the theoretical child phase orientations for a given orientation relationship between metal and oxide or between two oxide phases. The epitaxial relationships were found by starting with the substrate orientation, generating a large number of possible oxide orientations by incremental rotation of the oxide lattice in $3^{\circ}$ intervals until a match between the theoretical and experimental equal-area-projection pole figures was found. Then, the smallest Miller indices planes for these orientations was calculated within a $10^{\circ}$ tolerance. The misalignment between the theoretical and the experimental spots are most likely a result of combination of factors including error in the orientation measurement of the metal grain (e.g. some distortion in the sample when the oxide is polished off), the undulated interface between the metal and the oxide, and internal misorientation in the metal grain.

\section{References}

1. Koch, G. Cost of corrosion. in Trends in Oil and Gas Corrosion Research and Technologies: Production and Transmission 3-30 (Elsevier Inc., 2017). doi:10.1016/B978-0-08-101105-8.00001-2

2. Fushimi, K., Miyamoto, K. \& Konno, H. Anisotropic corrosion of iron in $\mathrm{pH} 1$ sulphuric acid. Electrochim. Acta 55, 7322-7327 (2010).

3. Horton, D. J., Zhu, A. W. \& Scully, J. R. Crystallographic controlled dissolution and surface faceting in disordered face-centered cubic FePd. MRS Commun. 4, 113-119 (2014).

4. Bland, L. G., Gusieva, K. \& Scully, J. R. Effect of Crystallographic Orientation on the Corrosion of Magnesium: Comparison of Film Forming and Bare Crystal Facets using Electrochemical Impedance and Raman Spectroscopy. Electrochim. Acta 227, 136151 (2016).

5. Yasuda, M., Weinberg, F. \& Tromans, D. Pitting Corrosion of Al and Al-Cu Single Crystals. J. Electrochem. Soc. 137, 3708-3715 (1990).

6. Davis, B. W., Moran, P. J. \& Natishan, P. M. Metastable pitting behavior of aluminum single crystals. Corros. Sci. 42, 2187-2192 (2000).

7. Kim, H. G., Kim, T. H. \& Jeong, Y. H. Oxidation characteristics of basal (0002) plane and prism (1120) plane in HCP Zr. J. Nucl. Mater. 306, 44-53 (2002).

8. Muller, M. \& Oechsner, H. In situ STM and AES studies on the oxidation of $\mathrm{Cr}(110)$. Surf. Sci. 387, 269-278 (1997).

9. Cathcart, J. V., Petersen, G. F. \& Sparks, J. C. J. The Structure of Thin Oxide Films Formed on Nickel Crystals. J. Electrochem. Soc. 116, 664 (1969).

10. Li, H., Czerwinski, F., Zhilyaev, A. \& Szpunar, J. A. Computer modelling the diffusion of Ni in NiO at high temperatures. Corros. Sci. 39, 1211-1219 (1997). 
11. Czerwinski, F. \& Szpunar, J. A. Controlling the surface texture of nickel for high temperature oxidation inhibition. Corros. Sci. 41, 729-740 (1999).

12. Gray, J. J., Dasher, B. S. El \& Orme, C. A. Competitive effects of metal dissolution and passivation modulated by surface structure: An AFM and EBSD study of the corrosion of alloy 22. Surf. Sci. 600, 2488-2494 (2006).

13. Young, F. W. J., Cathcart, J. V \& Gwathmeyf, A. T. The rates of oxidation of several faces of a single crystal of copper as determined with elliptically polarized light. Acta Metall. 4, 145 (1956).

14. Schuh, C. A., Anderson, K. \& Orme, C. Rapid assessment of anisotropic surface processes: experiments on the corrosion of Inconel 600. Surf. Sci. 544, 183-192 (2003).

15. Liu, M., Qiu, D., Zhao, M.-C. C., Song, G. \& Atrens, A. The effect of crystallographic orientation on the active corrosion of pure magnesium. Scr. Mater. 58, 421-424 (2008).

16. Abayarathna, D., Hale, E. B., O'Keefe, T. J., Wang, Y. M. \& Radovic, D. Effects of sample orientation on the corrosion of zinc in ammonium sulfate and sodium hydroxide solutions. Corros. Sci. 32, 755-768 (1991).

17. Davepon, B., Schultze, J. W., Konig, U. \& Rosenkranz", C. R. Crystallographic orientation of single grains of polycrystalline titanium and their influence on electrochemical processes. Surf. Coatings Technol. 169, 85-90 (2003).

18. Pemsler, J. P. Diffusion of oxygen in zirconium and its relation to oxidation and corrosion. J. Electrochem. Soc. 105, 315 (1958).

19. Ploc, R. A. A transmission electron diffraction study of $\mathrm{ZrO} 2$ on $\alpha-\mathrm{Zr}$ (0001). J. Nucl. Mater. 110, 59-64 (1982).

20. Bakradze, G., Jeurgens, L. P. H. \& Mittemeijer, E. J. The different initial oxidation kinetics of $\operatorname{Zr}(0001)$ and $\operatorname{Zr}(101-0)$ surfaces. J. Appl. Phys. 110, (2011).

21. Methfessel, M., Hennig, D. \& Schefber, M. Trends of the surface relaxations, surface energies, and work functions of the 41 transition metals. Phys. Rev. B 46, 4816-4829 (1991).

22. Błoński, P. \& Kiejna, A. Structural, electronic, and magnetic properties of bcc iron surfaces. Surf. Sci. 601, 123-133 (2007).

23. Chiang, T. W., Chernatynskiy, A., Noordhoek, M. J., Sinnott, S. B. \& Phillpot, S. R. Anisotropy in oxidation of zirconium surfaces from density functional theory calculations. Comput. Mater. Sci. 98, 112-116 (2015).

24. Zhang, J. M., Wang, D. D. \& Xu, K. W. Calculation of the surface energy of hcp metals by using the modified embedded atom method. Appl. Surf. Sci. 253, 2018-2024 (2006).

25. Lillard, R. S., Wang, G. F. \& Baskes, M. I. The role of metallic bonding in the cristallographic pitting of magnesium. J. Electrochem. Soc. 153, 358-364 (2006).

26. Noordhoek, M. J., Liang, T., Chiang, T.-W., Sinnott, S. B. \& Phillpot, S. R. Mechanisms of $\mathrm{Zr}$ surface corrosion determined via molecular dynamics simulations 
with charge-optimized many-body (COMB) potentials. J. Nucl. Mater. 452, 285-295 (2014).

27. Franchy, R. Â. Growth of thin, crystalline oxide, nitride and oxynitride films on metal and metal alloy surfaces. Surf. Sci. Rep. 38, 195-294 (2000).

28. Khoi, N. N., Smeltzer, W. W. \& Embury, J. D. Growth and Structure of Nickel Oxide on Nickel Crystal Faces. J. Electrochem. Soc. 122, 1495-1503 (1975).

29. Li, H., Glavicic, M. \& Szpunar, J. A. A model of texture formation in $\mathrm{ZrO} 2$ films. Mater. Sci. Eng. A 366, 164-174 (2004).

30. Tenckhoff, E. A review of texture and texture formation in Zircaloy tubing. Zircon. Nucl. Ind. 5th Int. Symp. ASTM STP 754 5-25 (1982).

31. Garner, A., Frankel, P., Partezana, J. \& Preuss, M. The effect of substrate texture and oxidation temperature on oxide texture development in zirconium alloys. $J$. Nucl. Mater. 484, 347-356 (2017).

32. Pilling, N. B. \& Bedworth, R. E. The oxidation of metals at high temperatures. J. Inst. Met 29, 529-591 (1923).

33. Dunn, J. S. The high temperature oxidation of metals. Proc. R. Soc. A Math. Phys. Eng. Sci. 111, 203-209 (1926).

34. Wei, J. et al. The effect of Sn on autoclave corrosion performance and corrosion mechanisms in Zr-Sn-Nb alloys. Acta Mater. 61, 4200-4214 (2013).

35. Stringer, J. Stress generation and relief in growing oxide films. Corros. Sci. 10, $513-$ 543 (1970).

36. Guerain, M., Duriez, C., Grosseau-Poussard, J. L. \& Mermoux, M. Review of stress fields in Zirconium alloys corrosion scales. Corros. Sci. 95, 11-21 (2015).

37. Heuer, A. H. \& Rühle, M. Overview no. 45. On the nucleation of the martensitic transformation in zirconia (ZrO2). Acta Metall. 33, 2101-2112 (1985).

38. Zhou, G. \& Yang, J. C. Initial oxidation kinetics of $\mathrm{Cu}(100),(110)$, and (111) thin films investigated by in situ ultra-high-vacuum transmission electron microscopy. $J$. Mater. Res. 20, 1684-1694 (2005).

39. Garner, A. et al. The microstructure and microtexture of zirconium oxide films studied by transmission electron backscatter diffraction and automated crystal orientation mapping with transmission electron microscopy. Acta Mater. 80, 159-171 (2014).

40. Qin, W., Nam, C., Li, H. \& Szpunar, J. Tetragonal phase stability in ZrO2 film formed on zirconium alloys and its effects on corrosion resistance. Acta Mater. 55, 1695-1701 (2007).

41. Nicholls, R. J. et al. Crystal Structure of the $\mathrm{ZrO}$ phase at zirconium/zirconium oxide interfaces. Adv. Eng. Mater. (2014). doi:10.1002/adem.201400133

42. Barberis, P. Zirconia powders and Zircaloy oxide films: tetragonal phase evolution during $400^{\circ} \mathrm{C}$ autoclave tests. J. Nucl. Mater. 226, 34-43 (1995).

43. Zhou, B. X., Li, Q., Yao, M. Y., Liu, W. Q. \& Chu, Y. L. Effect of water chemistry and composition on microstructural evolution of oxide on Zr-alloys. J. ASTM Int. 360 
44. Sabol, G. P. ZIRLO - an alloy development success. J. ASTM Int. 2 2, 1-22 (2005).

45. Davenport, A. J., Oblonsky, L. J., Ryan, M. P. \& Toney, M. F. The structure of the passive film that forms on iron in aqueous environments. J. Electrochem. Soc. 147, (2000).

46. Gong, W. et al. Grain morphology and crystal structure of pre-transition oxides formed on Zircaloy-4. Corros. Sci. 74, 323-331 (2013).

47. Ni, N. et al. How the crystallography and nanoscale chemistry of the metal/oxide interface develops during the aqueous oxidation of zirconium cladding alloys. Acta Mater. 60, 7132-7149 (2012).

48. Harlow, W., Lang, A. C., Demaske, B. J., Phillpot, S. R. \& Taheri, M. L. Thicknessdependent stabilization of tetragonal $\mathrm{ZrO} 2$ in oxidized zirconium. Scr. Mater. 145, 9598 (2018).

49. Baxter, F. et al. Phase stability of zirconium oxide films during focused ion beam milling. J. Nucl. Mater. 504, (2018).

50. Liu, L. New high pressure phases of ZrO2 and HfO2. J. Phys. Chem. Solids 41, 331334 (1980).

51. Fabris, S., Paxton, A. T. \& Finnis, M. W. A stabilization mechanism of zirconia based on oxygen vacancies only. Acta Mater. 50, 5171-5178 (2002).

52. Smith, D. K. \& Newkirk, W. The crystal structure of baddeleyite (monoclinic ZrO2 ) and its relation to the polymorphism of ZrO 2. Acta Crystallogr. 18, 983-991 (1965).

53. Romero, J., Preuss, M. \& Quinta Da Fonseca, J. Texture memory and variant selection during phase transformation of a zirconium alloy. Acta Mater. 57, 5501-5511 (2009).

54. Rauch, E. F. et al. Automatic crystal orientation and phase mapping in TEM by precession diffraction. Microsc. Anal. 128, S5-S8 (2008).

55. Hu, J. et al. Identifying suboxide grains at the metal-oxide interface of a corroded $\mathrm{Zr}-$ $1.0 \% \mathrm{Nb}$ alloy using (S)TEM, transmission-EBSD and EELS. Micron 69, 35-42 (2015).

56. Liu, J. et al. Mechanis $\mathrm{m}$ of the $\alpha-\mathrm{Zr}$ to hexagonal- $\mathrm{ZrO}$ transformation and its impact on the corrosion performance of nuclear Zr Alloys. Prep. (2019).

57. Yu, H., Yao, Z., Long, F., Saidi, P. \& Daymond, M. R. In situ transmission electron microscopy study of the thermally induced formation of $\delta^{\prime}-\mathrm{ZrO}$ in pure $\mathrm{Zr}$ and $\mathrm{Zr}$ based alloy. J. Appl. Crystallogr. 50, 1028-1035 (2017).

58. Luo, Y.\& Qin, R. Surface energy and its anisotropy of hexagonal close-packed metals. Surf. Sci. 630, 195-201 (2014).

59. Bakradze, G., Jeurgens, L. P. H. \& Mittemeijer, E. J. The different initial oxidation kinetics of $\operatorname{Zr}(0001)$ and $\operatorname{Zr}(100)$ surfaces The different initial oxidation kinetics of $\operatorname{Zr}(0001)$ and $\operatorname{Zr}(10$ 10) surfaces. Cit. J. Appl. Phys. 110, 1838 (2011).

60. Momma, K. \& Izumi, F. VESTA 3 for three-dimensional visualization of crystal, volumetric and morphology data. J. Appl. Crystallogr. 44, 1272-1276 (2011). 
61. Ogata, S., Li, J., Hirosaki, N., Shibutani, Y. \& Yip, S. Ideal shear strain of metals and ceramics. Phys. Rev. B 70, 104104 (2004).

62. Lin, J. et al. Analysis of zirconium oxide formed during oxidation at $623 \mathrm{~K}$ on $\mathrm{Zr}-$ 2.5Nb and Zircaloy-4. Mater. Sci. Eng. A 381, 104-112 (2004).

63. Motta, A. T. et al. Microstructural Characterization of Oxides Formed on Model Zr Alloys Using Synchrotron Radiation. J. ASTM Int. 5, 101257 (2008).

64. Spengler, D. J., Motta, A. T., Bajaj, R., Seidensticker, J. R. \& Cai, Z. Characterization of Zircaloy-4 corrosion films using microbeam synchrotron radiation. J. Nucl. Mater. 464, 107-118 (2015).

65. Gabory, B. D., Motta, A. T. \& Wang, K. Transmission electron microscopy characterization of Zircaloy-4 and ZIRLO oxide layers. J. Nucl. Mater. 456, 272-280 (2015).

66. Motta, A. et al. Microstructure and growth mechanism of oxide layers formed on $\mathrm{Zr}$ alloys studied with Micro-Beam synchrotron radiation. J. ASTM Int. 2, 1-26 (2005).

67. Parise, M., Sicardy, O. \& Cailletaud, G. Modelling of the mechanical behavior of the metal-oxide system during Zr alloy oxidation. J. Nucl. Mater. 256, 35-46 (1998).

68. Gass, M. et al. Corrosion of Zircaloys: Relating the microstructural observations to the corrosion kinetics. J. Nucl. Mater. 509, 343-354 (2018).

69. Mainprice, D., Bachmann, F., Hielscher, R. \& Schaeben, H. Descriptive tools for the analysis of texture projects with large datasets using MTEX: Strength, symmetry and components. Geol. Soc. 409, 251-271 (2014).

70. Garner, A. J. W. Investigating the effect of oxide texture on the corrosion performance of zirconium alloys. (University of Manchester, 2014).

\section{Acknowledgments}

Funding: Include all funding sources, including grant numbers, complete funding agency names, and recipient's initials. Each funding source should be listed in a separate paragraph such as:

The Engineering and Physical Sciences Research Council UK (EPSRC) through the Centre for Doctoral Training in Advanced Metallic Systems, EP/G036950/1 (MSY, $\mathrm{AG}, \mathrm{FB}, \mathrm{SA}$ )

The Engineering and Physical Sciences Research Council UK grand MIDAS EP/S01702X/1 (MP, CPR, PF)

University Research Fellowship of the Royal Society (CPR)

\section{Author contributions:}

Conceptualization: MSY, AG, FB, SA, CPR, MP, PF

Methodology: MSY, AG, FB, SA, CPR, MP, PF

Investigation: MSY, AG, FB, SA

Visualization: MSY, AG, FB, SA

Supervision: CPR, MP, PF

Writing - original draft: MSY, AG

Writing - review \& editing: MSY, AG, SA, CPR, MP, PF

Competing interests: Authors declare that they have no competing interests. 
Data and materials availability: All data needed to evaluate the conclusions in the paper are included in the paper and/or the Supplementary Materials. Additional data and Jupyter 


\section{Supplementary Files}

This is a list of supplementary files associated with this preprint. Click to download.

- Supplementarymaterial.pdf 